\title{
Enhanced Removal of Phosphates by the Adsorbent Consisting of Iron Oxide Loaded on Porous Chitosan/Cellulose Acetate Particle
}

\author{
Nancy M. Waweru',2, Jingjing Yang1, Herbert C. Bolokonya ${ }^{1}$ \\ ${ }^{1}$ Suzhou University of Science and Technology, Suzhou, China \\ ${ }^{2}$ Department of Civil Engineering, University of Nairobi, Nairobi, Kenya \\ Email:waweru_nancy@ymail.com, yjjnancy@163.com, chiwalo@outlook.com,nancy.mugure@uon bi.ac.ke
}

How to cite this paper: Waweru, N.M., Yang, J.J. and Bolokonya, H.C. (2019) Enhanced Removal of Phosphates by the Adsorbent Consisting of Iron Oxide Loaded on Porous Chitosan/Cellulose Acetate Particle. Engineering, 11, 366-394.

https://doi.org/10.4236/eng.2019.117027

Received: March 27, 2019

Accepted: July 14, 2019

Published: July 17, 2019

Copyright ( 2019 by author(s) and Scientific Research Publishing Inc. This work is licensed under the Creative Commons Attribution-NonCommercial International License (CC BY-NC 4.0).

http://creativecommons.org/licenses/by-nc/4.0/

\begin{abstract}
The effective and economical removal of phosphates from aqueous solution, mostly applied in waste water treatment, is one of the significant issues globally. Removal of phosphates ions in aqueous solution was analysed by chitosan blended with cellulose acetate, and iron oxide loaded chitosan-cellulose acetate adsorbents. The adsorbents were made in the form of beads. Batch experiments were performed to investigate the performance of the beads under various conditions on phosphate adsorption. Contact time, effect of initial phosphate concentration, adsorbent dosage, $\mathrm{pH}$ and temperature were investigated. Zeta potential measurements were also undertaken. The results showed that the adsorption process was highly $\mathrm{pH}$ dependent. The adsorption kinetics data were modelled with the application of adsorption reaction models and adsorption diffusion models. The results revealed that the pseudo 2nd order model was the best fitting in all cases. The experimental data were tested with Langmuir and Freundlich isotherms. The equilibrium data were well fitted to the Langmuir isotherm model with a maximum adsorption capacity of $958 \mu \mathrm{g} / \mathrm{g}$. The Freundlich isotherm model also had a close fit with a maximum adsorption of $233 \mu \mathrm{g} / \mathrm{g}$, which was very close to the experimental maximum adsorption. The mechanism of adsorption followed two stages in which the first one was fast followed by a slower gradual stage. SEM images showed that the adsorbent was macroporous. Fourier Transform Infrared Red (FT-IR) Spectroscopy, X-ray Diffraction Spectroscopy (XRD) and X-ray photoelectron Spectroscopy (XPS) showed that the phosphate adsorption on the HFO-CS/CA beads was due to surface complexes, and mainly involved Nitrogen atoms. HFO loading also increased surface area.
\end{abstract}

\section{Keywords}

Phopshates, Adsorption, Chitosan/Cellulose Acetate, Iron Oxides 


\section{Introduction}

Phosphate is the natural occurring form of phosphorus element that is essential to all life on earth. Its life-giving properties are key to a variety of cellular and biological processes that allow plants, animals and even humans to grow. Many of the most important biochemicals are organophosphates including ATP (Adenosine Triphosphate), DNA (Deoxyribonucleic acid), and RNA Ribonucleic acid). ATP is a chemical compound that breaks down to release energy in the body and a key stage in the Kreb's Cycle [1]. RNA and DNA are the backbones of life on this planet, via genetics. Therefore, the availability of phosphorus is a key factor controlling photosynthesis. It's for these reasons that phosphate is a highly sought after resource.

Industrial use of phosphates, mainly in the inorganic forms such as $\mathrm{PO}_{4}^{3-}$, $\mathrm{HPO}_{4}^{2-}$, and $\mathrm{H}_{2} \mathrm{PO}_{4}^{-}$, is a constituent of fertilizers, detergents and food additives. Once used, it is often a limiting nutrient in environments, and its availability may govern the rate of growth of organisms, especially in fresh water environments. Phosphates are present in the environment through run off from agricultural fields as it adheres tightly to soil [2], and also present in sewage via human waste and food residues. A normal adult excretes 1.3 - $1.5 \mathrm{~g}$ of phosphorus per day. Additional phosphorus originates from the use of industrial products, such as toothpaste, detergents, pharmaceuticals, and food-treating compounds.

Addition of high levels of phosphate to environments and to micro-environments in which it is typically rare can have significant ecological consequences. For example, blooms in the populations of some organisms at the expense of others, and the collapse of populations deprived of resources such as oxygen can occur. Eutrophication is one such, where algae populations explode forming mats as a result of being produced faster than they are consumed, diminishing the penetration of light into the water. This results in depletion of dissolved oxygen consequentially death of aquatic life.

The natural background levels of total phosphorus are generally less than 0.03 $\mathrm{mg} / \mathrm{l}$. The range is usually between 0.005 to $0.05 \mathrm{mg} / \mathrm{L}$ [3] [4]. Increased levels as low as $0.08 \mathrm{mg} / \mathrm{L}$ of $\mathrm{P}$ have been shown to cause excessive algae and plankton bloom. Although levels of 0.08 to $0.10 \mathrm{mg} / \mathrm{l}$ orthophosphate may trigger periodic blooms, long-term eutrophication will usually be prevented if total phosphorus levels and orthophosphate levels are below $0.5 \mathrm{mg} / \mathrm{l}$ and $0.05 \mathrm{mg} / \mathrm{l}$, respectively [4]. Therefore, removal of phosphates from waste water is a key issue in modern water treatment studies.

There are a number of techniques that have been put in use for removal of phosphates in wastewater. These are ion-exchange [5], reverse osmosis [6], precipitation [7], electrodialysis [8], and bioremediation [9], among others. Technically, these methods are not feasible and economical to meet the stringent regulations of phosphorous concentrations in effluent. They can lower the concentration of $\mathrm{P}$ to about $0.5-0.7 \mathrm{mg} / \mathrm{L}$ [10]. Therefore, more novel and advanced 
processes are being studied. In recent days, ion exchange and adsorption has shown tremendous potential use in waste water treatment [11]. Adsorption-based processes are advantageous when compared with other techniques in terms of the infrastructure cost, modular design, simplified technological design, and operation. The other important advantage to note is that with adsorption, pollutant values can be recovered along with their removal from the effluents. Use of materials of biological origins has shown to be more economical and environment friendly.

Chitosan, a derived from chitin after N-deacetylation process, has been found to be a good bio-adsorbent [12]. The protonation of the amine groups [13], in chitosan in acidic environment is important as pertaining to the adsorption of the negatively charged phosphate ions. The poor chemical stability and low mechanical strength of chitosan is improved by adding cellulose acetate which acts as a matrix polymer. It improves the strength and volume of the chitosan [11]. Studies have also shown hydrated iron oxides (HFO) to be effective in removal of ions from aqueous solutions, by formation of inner sphere complexes [14]. Their stability over a wide range of $\mathrm{pH}$ is an advantage. Research has shown that metal oxide/metal nanoparticles embedded in appropriate support materials enhance permeation of targets ionic solutes. In this study, the adsorption properties of chitosan are complemented by the complexation properties of HFO, whereas cellulose acetate increases porosity and strength of the material, and hence adsorption efficiency.

In this study, the main objective was met through a series of short term studies that were to synthesize, characterize, and study the adsorption properties of chitosan based bead materials with and without HFO loading, for physiochemical characterization based on potentioetry and adsorption measurements. A comparison of experimental parameters such as $\mathrm{pH}$, concentration of adsorbate, temperature, and dosage of adsorbent was done to provide information about the adsorption properties of the materials.

Complementary physiochemical structure and surface characterization study using Scanning electron microscopy (SEM), Fourier transform infra-red (FT-IR) Spectroscopy, X-ray powder diffraction (XRD) and X-ray photoelectron spectroscopy (XPS).

\section{Materials and Methods}

\subsection{Reagents and Materials}

Cellulose acetate and low molecular weight chitosan (Deacetylated chitin) were purchased from Shanghai Aldrich Company. Formate, $\mathrm{CH}_{2} \mathrm{O}_{2}$ (98\%), Potassium antimony tartrate trihydrate $\left(\mathrm{C}_{8} \mathrm{H}_{4} \mathrm{~K}_{2} \mathrm{O}_{12} \mathrm{Sb}_{2} \cdot 3 \mathrm{H}_{2} \mathrm{O}\right)$, ammonium molybdate $\left(\left(\mathrm{NH}_{4}\right)_{2} \mathrm{MoO}_{4}\right)$, Potassium dihydrogen phosphate $\left(\mathrm{KH}_{2} \mathrm{PO}_{4}\right)$ and ascorbic acid (99.99\%) were purchased from Shanghai Macklin Company. Iron (III) chloride hexahydrate $\left(\mathrm{FeCl}_{3} \cdot 6 \mathrm{H}_{2} \mathrm{O}\right)$ and all other chemicals were of reagent grade purity and Milli-Q water was used to prepare all solutions. All experiments were per- 
formed in triplicate. Glass flasks and beakers were used in all experiments.

\subsection{Preparation of Standards and Test Solutions}

A $50 \mathrm{mgP} / \mathrm{L}$ Phosphate stock solution was prepared by measuring $0.2197 \mathrm{~g}$ of $\mathrm{KH}_{2} \mathrm{PO}_{4}$ and dissolving it in some Milli-Q water in a $1000 \mathrm{ml}$ volumetric flask. Then $5 \mathrm{ml}$ of 1:1 $\mathrm{H}_{2} \mathrm{SO}_{4}$ was added to the solution and more Milli-Q water was added up to the $1000 \mathrm{ml}$ mark. Prior to measuring the $\mathrm{KH}_{2} \mathrm{PO}_{4}$, it was been pre-dried at $110^{\circ} \mathrm{C}$ for 2 hours and then allowed to cool in a desiccator. For the colorimetric determination of phosphates, $10 \%$ ascorbic acid was prepared by dissolving $10 \mathrm{~g}$ of ascorbic acid in Milli-Q water up to $100 \mathrm{ml}$ mark. This solution was stored in a dark bottle at $4^{\circ} \mathrm{C}$ and was stable for 4 weeks and after that discarded and another one prepared. The combined reagent for the molybdenum blue method was prepared by measuring $14.44 \mathrm{~g}$ of $\left(\mathrm{NH}_{4}\right)_{2} \mathrm{MoO}_{4}$ and dissolving it in Milli-Q water to make $100 \mathrm{ml}$ solution (solution A). Then $0.35 \mathrm{~g}$ of $\mathrm{C}_{8} \mathrm{H}_{4} \mathrm{~K}_{2} \mathrm{O}_{12} \mathrm{Sb}_{2} \cdot 3 \mathrm{H}_{2} \mathrm{O}$ was weighed and dissolved in Milli-Q water to make $100 \mathrm{ml}$ solution (solution B). Solution A was then put in $300 \mathrm{ml}$ of 1:1 $\mathrm{H}_{2} \mathrm{SO}_{4}$ slowly with stirring, then solution $\mathrm{B}$ was added to the above mixture and mixed thoroughly. This solution (was labelled as solution C) was also stored in in a dark glass bottle and was stable for two months.

\subsection{Synthesis of Adsorbent Material}

A $3 \mathrm{~g}$ amount of chitosan powdered flakes was put in a $200 \mathrm{ml}$ beaker. $12 \mathrm{~g}$ of cellulose acetate powder was also weighed and added into the beaker. Then 100 $\mathrm{ml}$ of formate was measured with a measuring cylinder and added to the same beaker. The mixture was then covered and mixed at $200 \mathrm{rpm}$ with a mechanical stirrer for 12 hours, at room temperature. The viscous chitosan-cellulose acetate solution was then injected in droplets into $4 \mathrm{M} \mathrm{NaOH}$ solution to form hydrogel beads, while stirring the $\mathrm{NaOH}$ solution on a magnetic stirrer at 300 r.p.m. The injection was done by using gravity to do the dropping of the viscous chitosan-cellulose acetate solution through a $50 \mathrm{ml}$ syringe. The beads were approximately $2-3 \mathrm{~mm}$ in sizes. The hydrogel beads were then allowed to stay in the $\mathrm{NaOH}$ solution with slow stirring (on a magnetic stirrer 300 r.p.m.) for another 12 - 24 hours for hardening. The hardened beads were then separated from the $\mathrm{NaOH}$ solution and washed with Milli-Q water until the solution $\mathrm{pH}$ became neutral. The beads were then air-dried at room temperature for $2-3$ days and stored ready for use. This material had no iron oxides on them and herein was referred as CS/CA beads.

For the iron oxide loaded beads, the same procedure was followed. After mixing the chitosan, cellulose and formate mixture for 12 hours, $0.5 \mathrm{~g}$ of hydrated ferric chloride $\left(\mathrm{FeCl}_{3} \cdot 6 \mathrm{H}_{2} \mathrm{O}\right)$ was added to the viscous mixture, followed with further stirring for 12 hours. Thereafter the injection and hardening and cleaning procedure above followed. Also, the beads were then air-dried at room temperature for 2 - 3 days and stored ready for use. This material was herein referred to as HFO-CS/CA beads. 


\subsection{Zeta Potential Measurement}

The zeta potential of the material was measured. The dried bead material was ground into a fine powder. A weighed amount of powdered material (optimal dosage weight) was put into a solution of $50 \mathrm{ml}$ Milli-Q water with different $\mathrm{pH}$ values $(2,4,5,7,9$, and 11$)$ in the $100 \mathrm{ml}$ conical flasks. The mixture was then shaken ( 160 r.p.m.) at $25^{\circ} \mathrm{C}$ for 24 hours. The samples were then sonicated for 1 hour to remove any loosely held agglomerates. Thereafter, the zeta potential of the material was then measured using the Brookhaven (90 Plus Zeta) Zeta potential analyzer.

\subsection{Surface Morphology Characterization and Spectroscopy}

\subsubsection{Scanning Electron Microscopy}

Scanning Electron Microscopy (SEM) was done to deliver images with information about the samples' topography and composition, using the Phenom Pro desktop SEM with a backscattered detector. SEM images were taken at different resolutions and magnification for both HFO-CS/CA and CS/CA beads before and after air drying.

\subsubsection{Fourier Transform Infrared (FTIR) Spectroscopy}

Some of the dried CS/CA beads and HFO-CS/CA beads were separately ground into a fine powder using an electrical grinder machine. Approximately $0.1 \%$ $1.0 \%$ sample was well mixed with $\mathrm{KBr}$ powder with a mortar and pestle, into a homogenous material. A force of approximately 8 tons was then applied for several minutes to form transparent pellets. Then the Nicolet-6700 FT-IR machine was used to analyse the sample.

\subsubsection{Powder X-Ray Diffraction (XRD)}

Some of the dried CS/CA beads HFO-CS/CA beads, before and after adsorption, were separately ground into a fine powder using an electrical grinder machine. Then the sample was homogenized with a binder in a pestle and mortar, and then pressed in the ring to get a mechanical stable sample. XRD is a rapid analytical technique used for phase identification of crystalline material and provides information of unit cell dimensions. X-rays generated in the cathode ray tube are collimated and directed onto the samples, as the sample and detector are rotated the reflected ray is recorded. The interaction of the sample and incident ray produces constructive interference hence diffracted rays. A study of these diffracted rays allows the identification of the material composition and characteristics. The diffraction rays peaks are converted into d-spacing models and each mineral or compound has a set of unique d-spacings. Thermo-fisher scientific XRD analyzer was used.

\subsubsection{X-Ray Photoelectron Spectroscopy (XPS)}

The ground CS/CA beads HFO-CS/CA samples were also analyzed using Thermo-fisher scientific XPS equipment. This is a surface-sensitive quantitative spectroscopic technique that measures the elemental composition, empirical for- 
mula, chemical state and electronic state of the elements that exist within a material. A beam of X-rays is radiated on the material while simultaneously measuring the energy and number of electrons that escape from the top $0-10 \mathrm{~nm}$ of the material being analysed. Thus, the XPS spectra are obtained which are used to identify the elements present.

\subsection{Batch Adsorption Experiments}

Batch experiments were carried out with a $\mathrm{pH}$ range of 2 - 11. $0.1 \mathrm{M} \mathrm{HCl}$ and 0.1 $\mathrm{M} \mathrm{NaOH}$ was used to adjust the $\mathrm{pH}$ of the solutions. Unless stated otherwise, the sampling volume and measurements were performed in this route. First, a volume of the sample was taken out of the flask and filtered through $0.45 \mu \mathrm{m}$ membrane filters into $50 \mathrm{ml}$ test tubes up to the $25 \mathrm{ml}$ mark. Then Milli-Q water was added to dilute up to the $50 \mathrm{ml}$ mark. $1 \mathrm{ml}$ of ascorbic acid was added into the solution in test-tube, and after 30 seconds $2 \mathrm{ml}$ of reagent solution C (see Section 2.2) was added. The mixture was allowed to stay for 15 minutes for colour development and it was analysed thereafter using Shimadzu UV-3600 UV-VIS-NIR spectrophotometer at the detection wavelength of $700 \mathrm{~nm}$. The adsorption capacity of phosphate was estimated according to equations 2.1 to 2.3:

$$
\begin{gathered}
q t=(C o-C t) \times V / m \\
q e=(C o-C e) \times V / m \\
R e=(C o-C e) / C o \times 100 \%
\end{gathered}
$$

where $q t$ is the adsorption capacity at time $t(\mathrm{~min}), q e$ is the amount adsorbed at equilibrium, $C o$ is the initial phosphate concentration $(\mathrm{mgP} / \mathrm{L}), C e$ is the equilibrium $\mathrm{P}$ concentration $(\mathrm{mgP} / \mathrm{L}), V$ is the sample solution volume $(L), m$ is the mass of adsorbent used ( $\mathrm{g}$ ), and $R e$ is the removal efficiency at the adsorption equilibrium.

\subsubsection{Determination of Optimal Adsorption Time}

$50 \mathrm{ml}$ solution of $2 \mathrm{mgP} / \mathrm{L} \mathrm{KH}_{2} \mathrm{PO}_{4}$ was measured and added into a series of 100 $\mathrm{ml}$ conical flasks. The $\mathrm{pH}$ of the solutions was first adjusted to $\mathrm{pH} 7.0 \pm 0.2 \mathrm{using}$ $0.1 \mathrm{M} \mathrm{NaOH}$ and $0.1 \mathrm{M} \mathrm{HCl}$. The $\mathrm{pH}$ was being measured using an electronic $\mathrm{pH}$ meter. Portion of bead material, both HFO-CS/CA and CS/CA beads, were weighed $(0.05 \mathrm{~g})$ and added into the conical flasks. The flasks were put in a shaker (160 r.p.m.) at $25^{\circ} \mathrm{C}$. Samples were analysed at specific times to determine the concentration of $\mathrm{P}$ left in the solution.

\subsubsection{Determination of Optimal Adsorbent Dosage}

$50 \mathrm{ml}$ solution of $2 \mathrm{mgP} / \mathrm{L} \mathrm{KH}_{2} \mathrm{PO}_{4}$ was measured and added into a series of 100 $\mathrm{ml}$ conical flasks. The $\mathrm{pH}$ was adjusted as in 2.6 .1 above to $\mathrm{pH} 7.0 \pm 0.2$ for all samples. Portions of sorbent of different weights were added into the flasks. Then the mixture was put into a shaker (160 r.p.m.) at $25^{\circ} \mathrm{C}$, at a constant time as determined in point 2.6.1. Samples were then analysed to determine the concentration of $\mathrm{P}$ left in the solution, and hence establish the optimum dosage for sorption. 


\subsubsection{Determination of Optimal Initial $P$ Concentration}

The $\mathrm{pH}$ of the samples was adjusted to $\mathrm{pH} 7.0 \pm 0.2$ for all samples, adsorbent was weighed as according to weight determined in 2.6 .2 above. Then the mixture was put into a shaker (160 r.p.m.) at $25^{\circ} \mathrm{C}$, at a constant time as determined in Point 2.6.1. Samples were then analysed to determine the concentration of $\mathrm{P}$ left in the solution, and hence establish the optimum initial $\mathrm{P}$ concentration to be used in this study.

\subsubsection{Determination of Optimal $\mathrm{pH}$}

$50 \mathrm{ml}$ solution of $\mathrm{KH}_{2} \mathrm{PO}_{4}$ was measured with the concentration of $\mathrm{P}$ determined in 2.6.3 and added into a series of $100 \mathrm{ml}$ conical flasks. The $\mathrm{pH}$ of the solution was adjusted as described above, to different $\mathrm{pH}$ values $(2,4,5,7,9$, and 11$)$. The same procedure was repeated for all samples, shaking (160 r.p.m.) at $25^{\circ} \mathrm{C}$ for time and adsorbent dosage determined in 2.6.1 and 2.6.2 respectively. Samples were then analysed to determine the concentration of $\mathrm{P}$ left in the solution, and thus the optimal $\mathrm{pH}$ where maximum adsorption took place.

\subsubsection{Determination of Effect of Temperature on Adsorption}

$50 \mathrm{ml}$ solution of $\mathrm{KH}_{2} \mathrm{PO}_{4}$ was measured with the concentration of $\mathrm{P}$ determined in 2.6.3 and added into a series of $100 \mathrm{ml}$ conical flasks. The $\mathrm{pH}$ was adjusted using $0.1 \mathrm{M} \mathrm{NaOH}$ and $0.1 \mathrm{M} \mathrm{HCl}$ to the optimal pH determined in 2.6.4 above. Portions of the HFO-CS/CA adsorbent were weighed as determined in 2.6.2 above and added to the solution. The mixtures were then put in shakers (160 r.p.m.) with different temperatures $\left(15^{\circ} \mathrm{C}, 25^{\circ} \mathrm{C}, 35^{\circ} \mathrm{C}\right.$ and $\left.50^{\circ} \mathrm{C}\right)$ and left for a time as determined in 2.6.1. Samples were then analysed to determine the concentration of $\mathrm{P}$ left in the solution, and hence establish the effect of temperature on adsorption.

\subsection{Effect of Co-Existing Ions}

The anions present in water such as $\mathrm{SO}_{4}^{2-}, \mathrm{Cl}^{-}, \mathrm{NO}_{3}^{-}$, and $\mathrm{CO}_{3}^{2-}$ might affect the adsorption of phosphates by competing for adsorption sites. To investigate the competing effect of coexisting anions on the adsorption of phosphate onto the bead material, $\mathrm{Na}_{2} \mathrm{SO}_{4}, \mathrm{NaCl}, \mathrm{NaNO}_{3}$ and $\mathrm{Na}_{2} \mathrm{CO}_{3}$ were used to prepare solutions with varying concentrations of the anions which were added to the phosphate solutions of a fixed P concentration. $0.5 \mathrm{mM}, 1.0 \mathrm{mM}$ and $5.0 \mathrm{mM}$ concentrations of $\mathrm{SO}_{4}^{2-}, \mathrm{Cl}^{-}, \mathrm{NO}_{3}^{-}$and $\mathrm{CO}_{3}^{2-}$ anions were used for the study. For all experiments, the initial concentration of phosphate was $1.2 \mathrm{mgP} / \mathrm{L}$ and that of the absorbent was as determined in 2.6.2. All the experiments were conducted in solutions at $\mathrm{pH}=7.0 \pm 0.2$ and shaken at a rate of 160 r.p.m for a time determined in 2.6 .1 at $25^{\circ} \mathrm{C}$.

\subsection{Regeneration Studies}

The re-use of the bead material was studied by establishing the removal efficiency of an optimized HFO-CS/CA bead system re-used for a number of cycles. A cycle of adsorption-desorption experiments was performed. First, the beads 
were rinsed with Milli-Q water to remove the surface phosphate solution. Then, desorption was achieved by washing the bead adsorbed phosphate using solutions of $\mathrm{NaCl}$ and $\mathrm{NaOH}$ solution for a period of 24 hours in orbital shaker (160 r.p.m.) at $25^{\circ} \mathrm{C}$ just like in the batch adsorption experiments. $10 \% \mathrm{NaCl}$ and $1 \mathrm{M}$ $\mathrm{NaOH}$ solutions. For some tests the beads (after desorption cycle) were rinsed with dilute $\mathrm{HCl}$ solution ( $\mathrm{pH}$ 4) before the next adsorption cycle. The phosphate concentration as determined like in the other experiments using the UV-Vis spectrophotometer. The adsorption capacity was determined for each adsorption cycle.

\section{Results and Discussion}

\subsection{Surface Morphology}

The colour of the HFO-CS/CA beads after drying was dark-brown-reddish colour, while the colour of the CS/CA beads was white. The dark-brown-reddish in the HFO-CS/CA is attribute to the ferric oxides in the material. The SEM images shown in Figures 1-3 showed that both the HFO-CS/CA and CS/CA beads were porous. The outer surface layer of the beads was amorphous as seen above, while the inner core had a layered textural porosity as shown below. The SEM backscatter micrographs of the beads were obtained using an acceleration of $20 \mathrm{keV}$.

\subsection{FT-IR Spectroscopy}

Fourier Transform Infrared Spectroscopy (FTIR analysis or FTIR Spectroscopy) is an analytical technique used to identify organic, polymeric, and in some cases, inorganic materials. It is a qualitative analysis of the molecular structure of a material. The FT-IR spectra of the chitosan based beads were as given in Figure 4.

Significant changes between the HFO-CS/CA and CS/CA in the FT-IR spectra are found the wavenumbers $2360.37 \mathrm{~cm}^{-1}$ and $2343.19 \mathrm{~cm}^{-1}$. This may be due to the iron oxides loading on the CS/CA material. To demonstrate the accomplishment

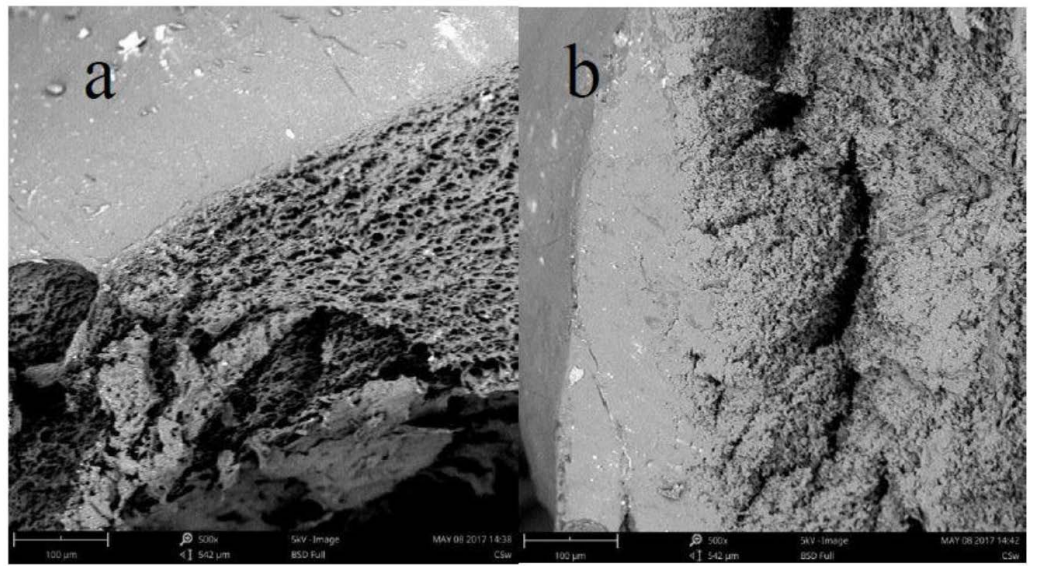

Figure 1. SEM images of the surface and cross-section of (a) wet, (b) dry, CS/CA beads. 


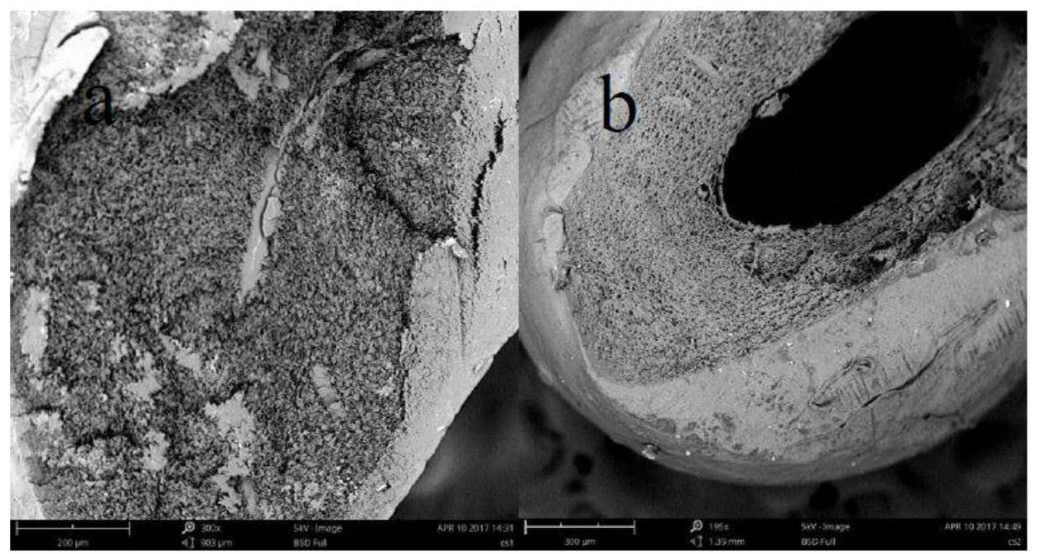

Figure 2. SEM images of the surface and cross-section of (a) dried (b) wet, HFO-CS/CA beads.

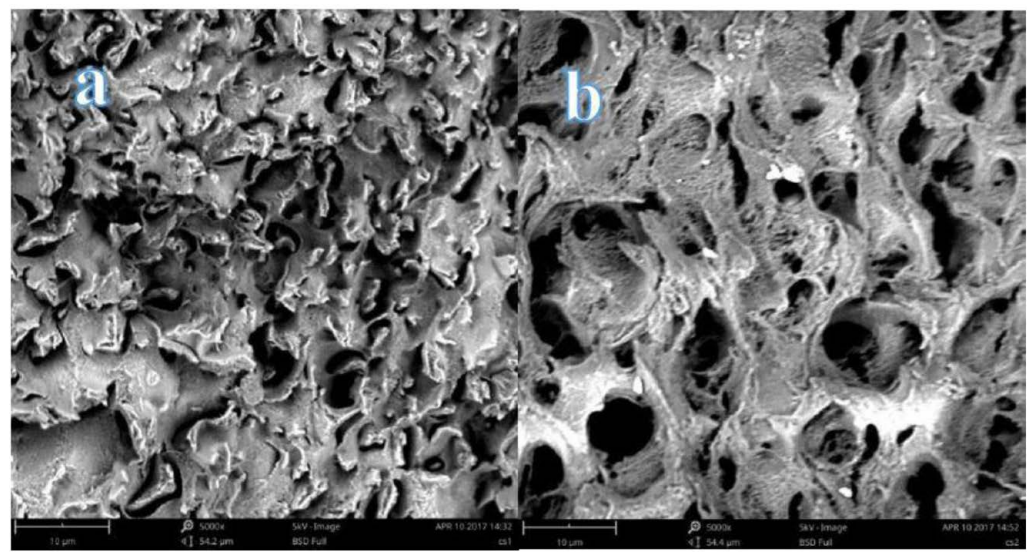

Figure 3. SEM images of the interior core of (a) dried (b) wet, HFO-CS/CA beads.

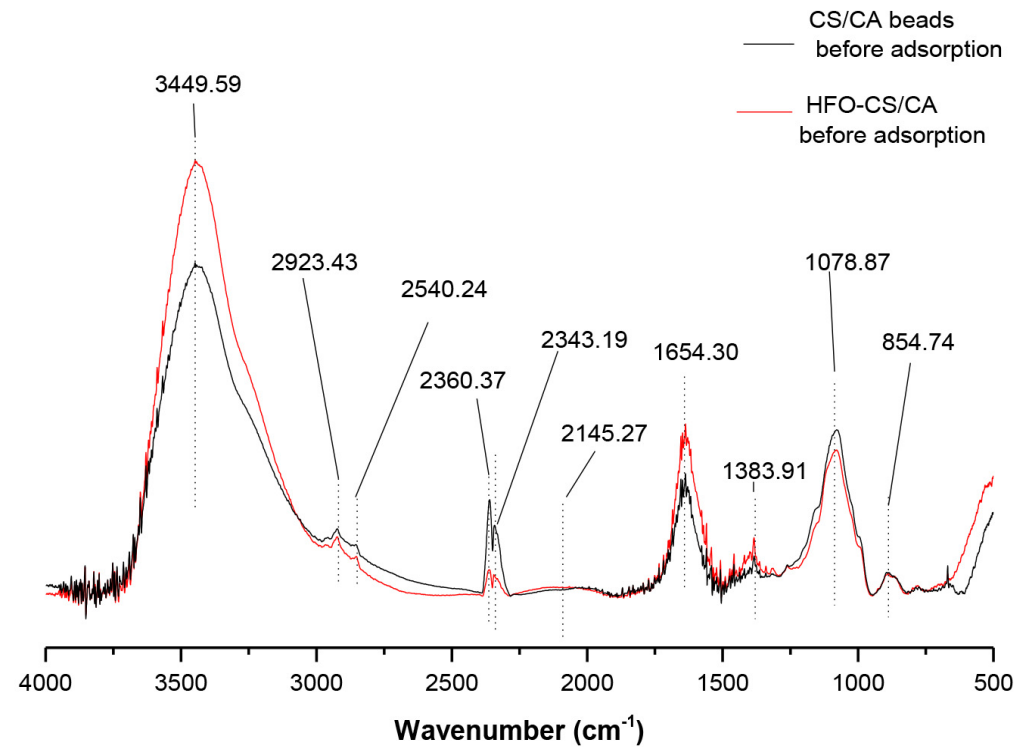

Figure 4. FT-IR Spectra of the CS/CA beads and HFO-CS/CA beads before adsorption. 
of phosphates adsorbed on the HFO-CS/CA, the changes in the spectra for HFO-CS/CA before and after phosphate adsorption were compared (Figure 5). The changes at $2145.27 \mathrm{~cm}^{-1}$ and $850 \mathrm{~cm}^{-1}$ may suggest $-\mathrm{OH}$ stretching vibration on the alcohol group [15]. There was a reduction in the band at $1320 \mathrm{~cm}^{-1}$ suggesting a reduction on intensity of $-\mathrm{OH}$, meaning surface hydroxyl groups had been replaced by adsorbed phosphate. A shift is observed between $800 \mathrm{~cm}^{-1}$ to $550 \mathrm{~cm}^{-1}$ which suggested N-H wagging/bending [15] [16], or shifts in H-bonding, a possibility due to adsorption. At $3500 \mathrm{~cm}^{-1}$ to $3300 \mathrm{~cm}^{-1}$ was the $\mathrm{N}-\mathrm{H}$ stretching region. Also at $2200 \mathrm{~cm}^{-1}$ to $2000 \mathrm{~cm}^{-1}$, there is an observable change with the transmission lowering suggesting $\mathrm{PO}-\mathrm{H}$ bonds.

\subsection{Powder X-Ray Diffraction (XRD)}

XRD sampling was done to allow identification of the material composition and probable unit cell dimensions, and its characteristics especially its crystallinity. Shown in Figure 6 are the spectra and data from the analysis.

The XRD spectra implied the CS/CA and HFO-CS/CA are semi-crystalline in nature, as the peaks obtained at about $2 \theta \approx 20.5$ were broad. The spectra for HFO-CS/CA beads before adsorption show a broader peak, with a second minor two peaks being observed at $2 \theta \approx 20.5$ and $2 \theta \approx 23.5$, with the latter being more visible. This implied iron oxides loading, and suggested that the sample was going from semi-crystalline to more amorphous nature [17]. Although the CS/CA beads has a narrower peak compared to HFO-CS/CA beads, the peak intensity for HFO-CS/CA beads is slightly lower than for CS/CA beads. This suggested that the average unit cell dimension in HFOCS/CA was reduced due to HFO loadings [18]. After adsorption, the HFO-CS/CA used beads still showed a broader peak, however, the peak intensity at $2 \theta \approx 23.5$ becomes more noticeable. This may have been due to a lesser true sum of all the diffracted X-ray photons

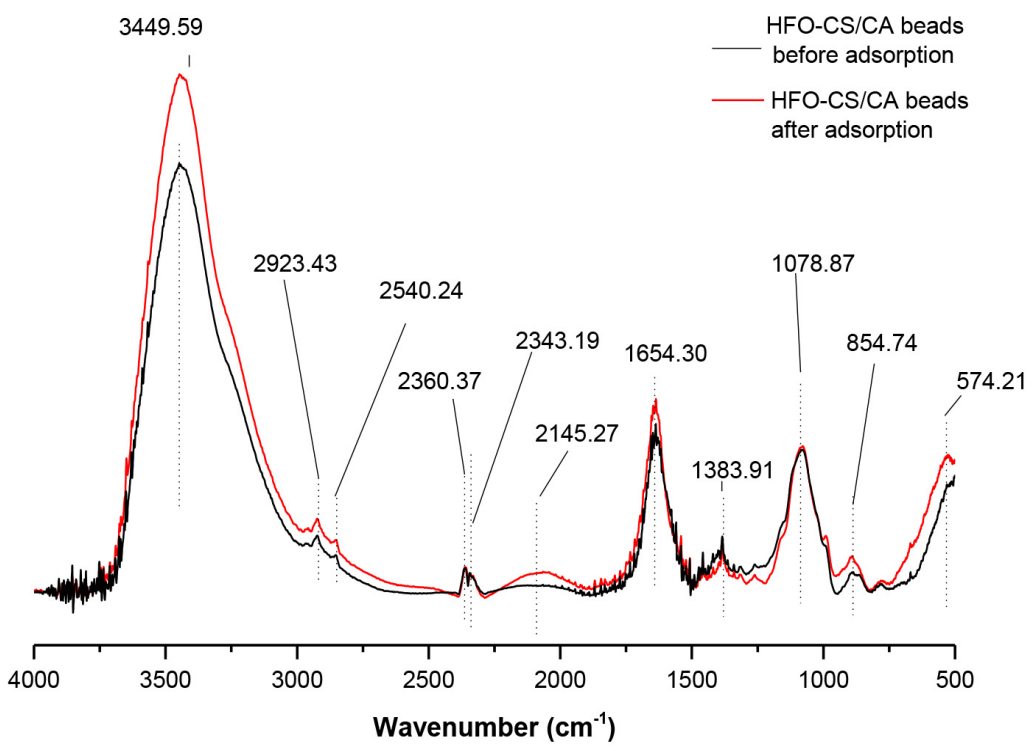

Figure 5. FT-IR spectra of HFO-CS/CA before and after phosphates adsorption. 


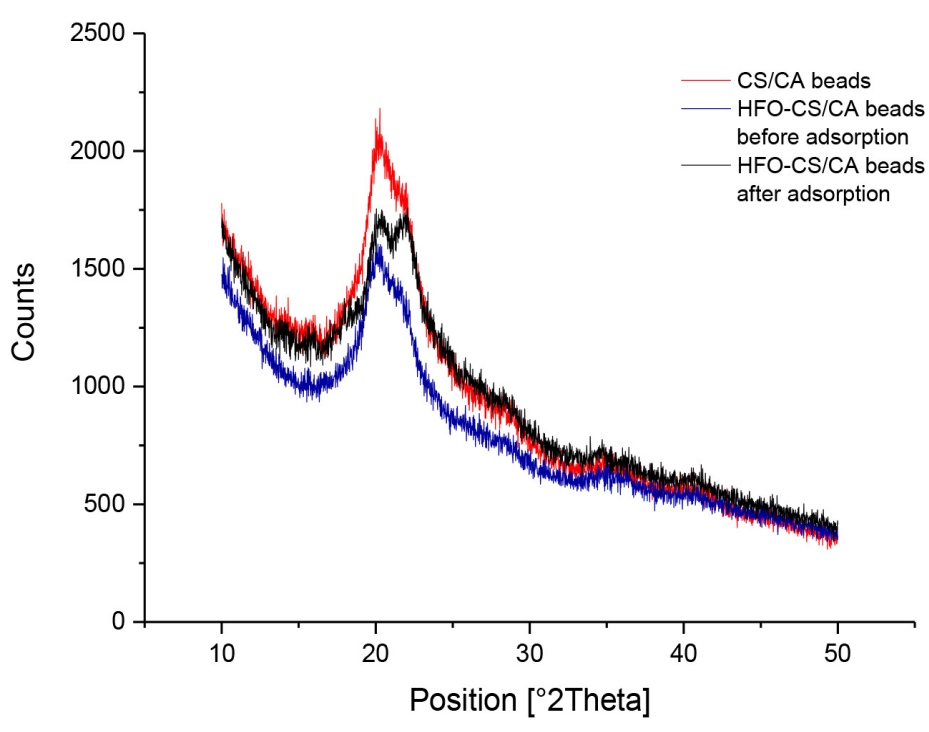

Figure 6. XRD spectra of the CS/CA beads with no adsorption and, HFO-CS/CA beads before and after phosphate adsorption.

(or neutrons) that had been detected, suggesting change due to phosphate loading [18]. The interaction detected in this study decreases the membrane crystallinity.

\subsection{X-Ray Photoelectron Spectroscopy (XPS)}

CS/CA beads HFO-CS/CA samples were analyzed using XPS analyzer to determine quantitatively the elemental composition, empirical formula, chemical state and electronic state of the elements that exist within a material. The different XPS spectra are as shown below.

Figure 7 shows the presence of a new peak at around $710.38 \mathrm{eV}$ that is absent in Figure 8, signifying iron loading. From the survey image, iron is effectively loaded on the CS/CA. Similarly, after adsorption phosphate shows in the image. This is clearly shown in Figure 9, where there's a new band at $133 \mathrm{eV}$ that is absent in Figure 7, (i.e. band present after adsorption), suggesting the loading with phosphates.

In Figure 10(a) and Figure 10(b), the typical $\mathrm{N}$ 1s XPS spectra of the HFO-CS/CA beads before and after adsorption were compared. There is only 1 peak at $399.3 \mathrm{eV}$. This was attributed to the $\mathrm{N}$ atom in the $-\mathrm{NH}_{2}$ and/or $-\mathrm{NH}-$ groups on surface the beads [11]. After adsorption, a new peak appears at 402.1 $\mathrm{eV}$. Referenced from other studies [11] [15] [17], this was an indicator that some $\mathrm{N}$ atoms existed in a more oxidized state on the beads surface due to phosphate adsorption. This phenomenon can be attributed to the formation of surface complexes, in which a lone pair of electrons in the $\mathrm{N}$ atom was donated to shared bonds in the complexes, and as a result electron cloud density of $\mathrm{N}$ is reduced. The XPS spectra provided evidence that phosphate binding to the HFO-CS/CA beads. 


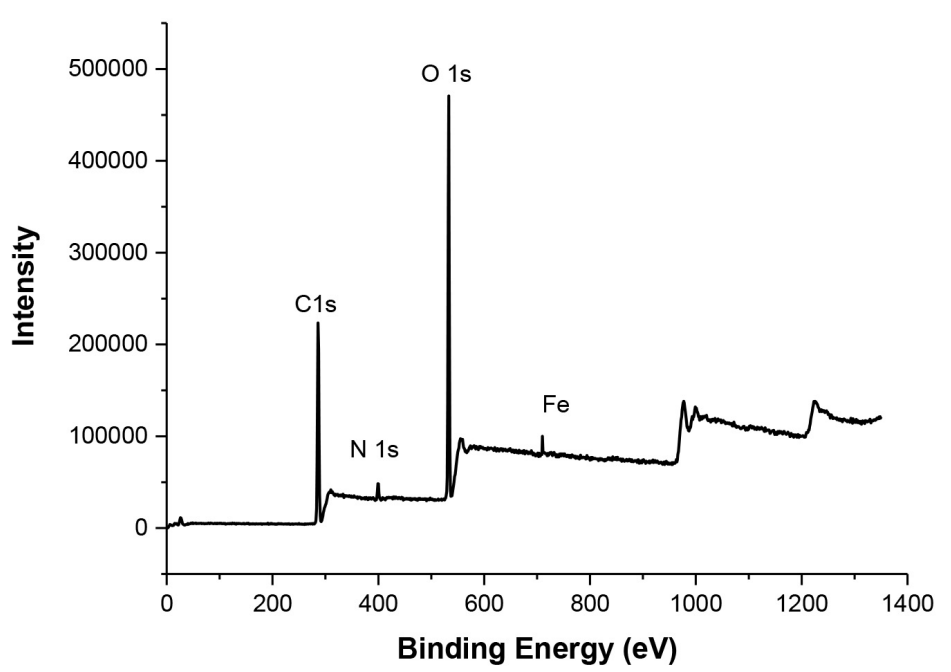

Figure 7. XPS spectrum of HFO-CS/CA beads before phosphate adsorption.

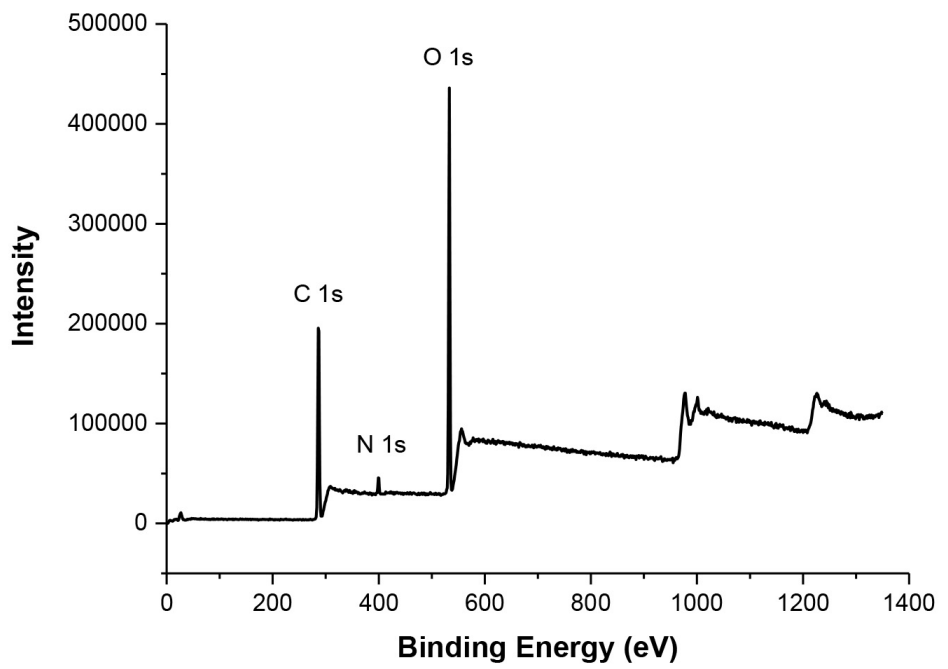

Figure 8. XPS spectrum of CS/CA beads.

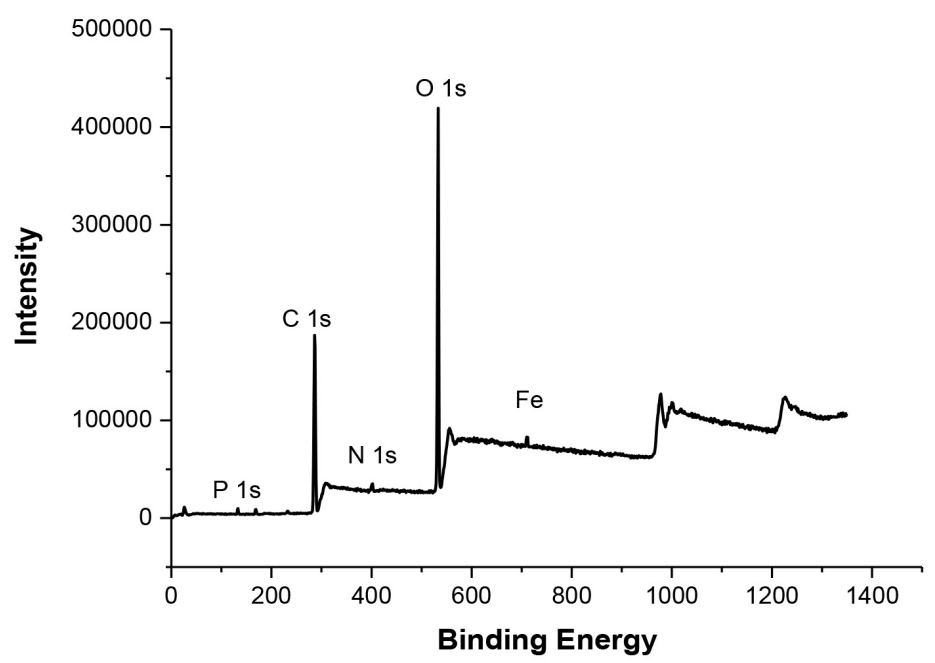

Figure 9. XPS spectrum of HF0-CS/CA beads after phosphate adsorption. 


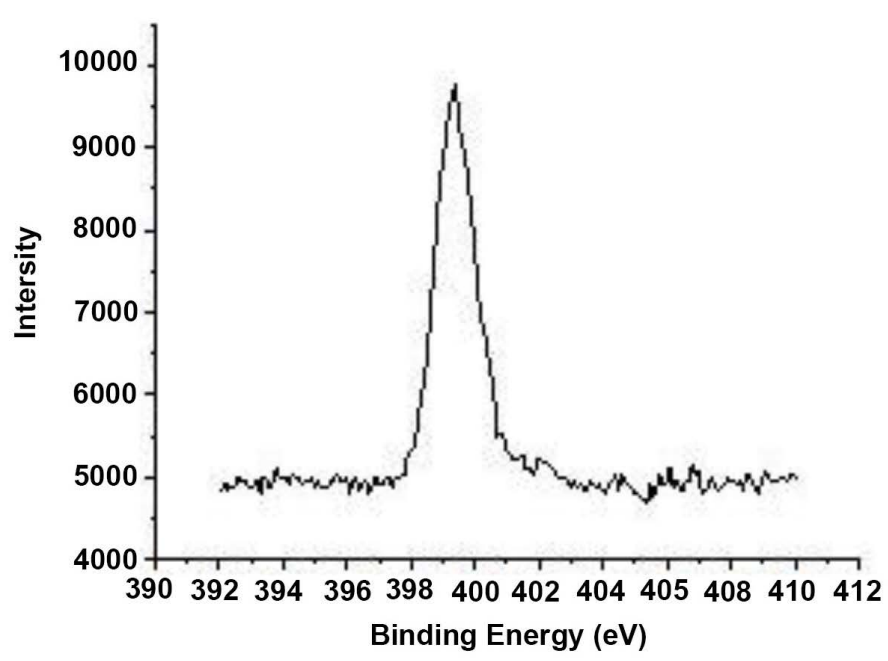

(a)

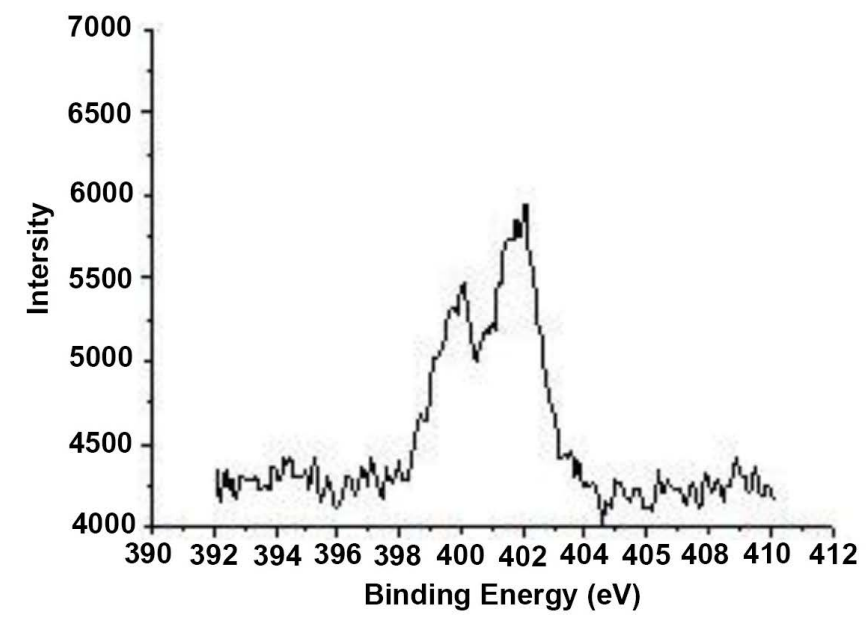

(b)

Figure 10. N 1s XPS spectra for iron loaded chitosan cellulose acetate beads before (a) and after (b) phosphate adsorption.

\subsection{Properties Affecting Adsorption}

\subsubsection{Effect of Reaction Time on the Adsorption of $\mathbf{P}$}

The time of adsorption was varied from 0 to 48 hours. For the preliminary investigation, it was observed that at the first 60 minutes, the removal efficiency decreased from $9.5 \%$ to $6.5 \%$ and then started rising. As time further increased, the efficiency also increased to $30 \%$ for HFO-CS/CA beads and about $17 \%$ for CS/CA beads after 1 hour. It was observed for both adsorbent material that after 24 hours, there was no significant change in the concentration. Hence equilibrium had been reached. At optimum adsorbent dosage, samples tested at 24 hours showed an $82 \%$ and $71 \%$ removal efficiency by HFO-CS/CA and CS/CA beads respectively. After 24 hours, there was no significant change in adsorption. For the next period of 24 hours the change was about $1.09 \%$ which was considered negligible. 
Figure 11 shows that the adsorption capacity increased rapidly in the beginning and then gradually to equilibrium. As time progressed, the adsorbent surface had been covered and all affinity site almost used up so no adsorption takes place. The anions are in equilibrium and hence no much change between the solid phase and the solution phase. Saturation of adsorption sites had occurred approximately at 24 hours. In all cases, the HFO-CS/CA bead material had a better removal efficiency and adsorption capacity as compared to CS/CA beads. The contact time was similar to theoretical time from literature review.

\subsubsection{Effect of Adsorbent Dosage the Adsorption of $P$}

During the adsorbent dosage studies, it was observed that as the dosage was increased so did the removal efficiency from as low as $51 \%$ at $1 \mathrm{~g} / \mathrm{L}$ to about $90 \%$ at $6 \mathrm{~g} / \mathrm{L}$ of HFO-CS/CA. CS/CA beads also followed a similar trend with the removal efficiency increasing from $38 \%$ to $57 \%$ for the same range of adsorbent. However, with a further increase in the adsorbent dosage the reaction reached equilibrium at optimum dosage and thereafter the efficiency started to decrease. From Figure 12, the absorbent dosage was established to be $6 \mathrm{~g} / \mathrm{L}$ with an efficiency of $89 \%$ for HFO-CS/CA adsorbent. For the CS/CA beads, an optimum was not reached within the range meaning more material needed to be used to achieve the same adsorption as the iron loaded material.

However, as the removal efficiency increased the adsorption capacity reduced with a further increase in adsorbent dosage as shown in Figure 12. Initially, at lower adsorbent dosage the number of amine and hydrated iron oxides active sites for adsorption are high, as the adsorbent concentration is increased the particle aggregation increases and as a result adsorption reduces. This phenomenon can also be attributed to the underutilization of adsorption sites especially at low concentrations of adsorbate.

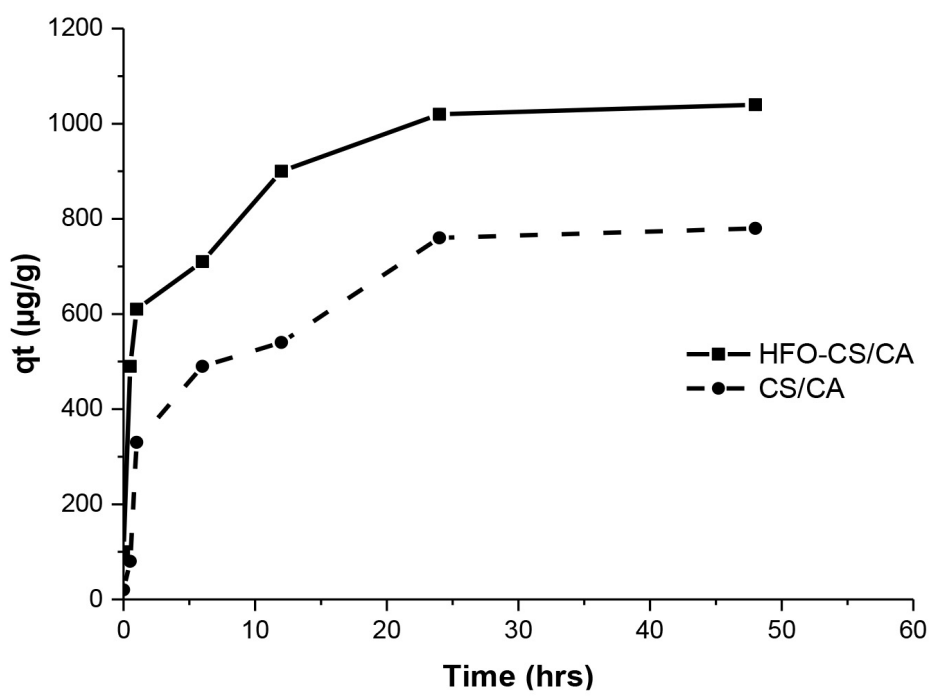

Figure 11. Effect of time on adsorption capacity of HFO-CS/CA and CS/CA beads (Adsorption conditions: Co $=2 \mathrm{mgP} / \mathrm{L}$, temp. $25^{\circ} \mathrm{C}$, adsorbent $1 \mathrm{~g} / \mathrm{L}, \mathrm{pH}=7.0 \pm 0.02)$. 


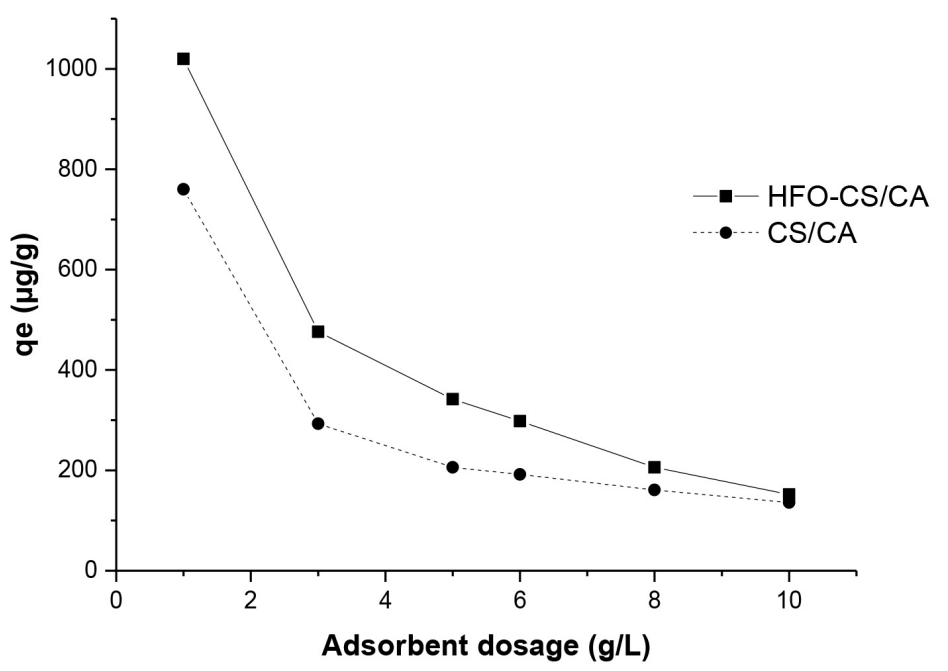

Figure 12. Effect of adsorbent dosage on adsorption capacity of HFO-CS/CA and CS/CA beads (Adsorption conditions: $\mathrm{Co}=2 \mathrm{mgP} / \mathrm{L}$, temp. $25^{\circ} \mathrm{C}$, time $24 \mathrm{hrs}, \mathrm{pH}=7.0 \pm 0.02$ ).

\subsubsection{Effect of Initial Concentration}

The removal efficiency dependency on the initial concentration of the adsorbate is shown in Figure 13. All other parameters were kept constant and the initial phosphate concentration was varied from $0.2 \mathrm{mg} / \mathrm{L}$ to $10 \mathrm{mg} / \mathrm{L}$. It was observed that at lower concentrations the efficiency increased rapidly as concentration of adsorbate increased in small ranges of about $0.4 \mathrm{mg} / \mathrm{L}$, to an optimum and then started to decrease. With a further increase in concentration the change was only less. It can also be seen that the optimum concentration for HFO-CS/CA adsorbent and CS/CA vary with the latter being achieved at a higher concentration of about $3 \mathrm{mgP} / \mathrm{L}$ compared to the former at about $1.2 \mathrm{mgP} / \mathrm{L}$. In this study, 1.2 $\mathrm{mgP} / \mathrm{L}$ was chosen for investigation because after secondary waste water treatment, the concentration of phosphates is in the range of $1.0 \mathrm{mgP} / \mathrm{L}-1.5 \mathrm{mgP} / \mathrm{L}$.

The adsorption capacity, unlike the removal efficiency, continued to increase with a further increase in initial concentration. This was attribute to the fact that the increase of phosphate ions resulted in a shift in the direction of the reaction and hence a further increase in adsorption of particles. There were particles available to shift form the aqueous phase to the solid phase to balance the system. This trend was observed for both HFO-CS/CA and CS/CA adsorbents. HFO-CS/CA adsorbent showed greater adsorption capacity as compared to CS/CA beads.

\subsubsection{Effect of $\mathrm{pH}$ and Determination of Zeta Potentials}

Maximum removal of phosphates was higher at almost neutral $\mathrm{pH}$. The $\mathrm{pH}$ was increased from 2 to 11, and the removal efficiency of HFO-CS/CA beads initially increased form $42 \%$ to about $75 \%$ at $\mathrm{pH}$ 6-7 as shown in Figure 14. As the $\mathrm{pH}$ was increased further the removal efficient dropped significantly. It was observed that for the CS/CA beads, the maximum removal efficiency of about 50\% was at $\mathrm{pH} 5$, a $\mathrm{pH}$ lower than that of the former. 


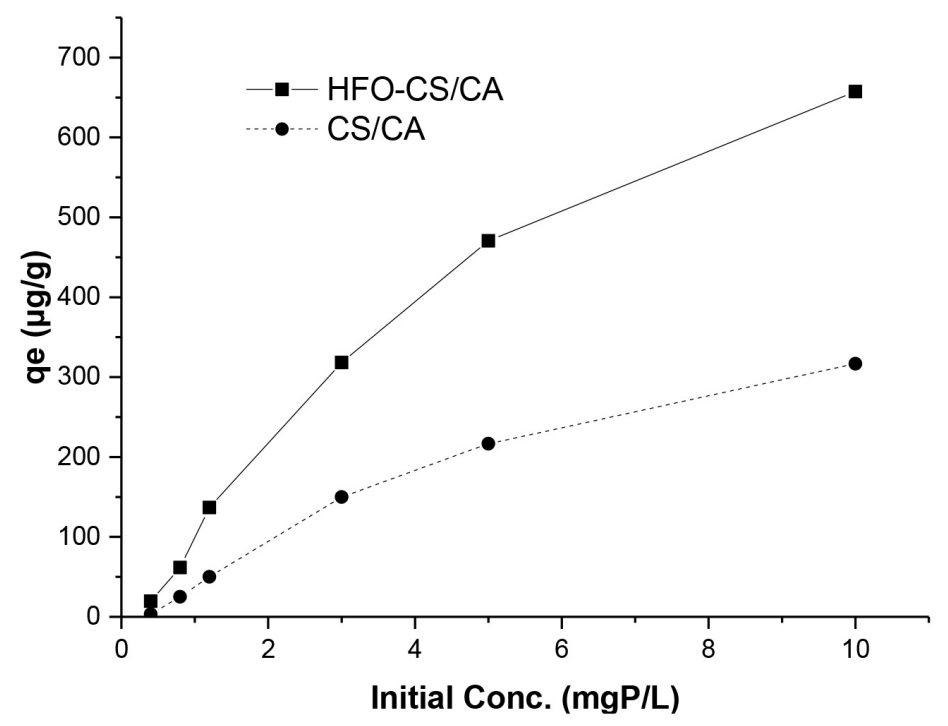

Figure 13. Effect of initial concentration on the beads adsorption capacity of phosphates (Adsorption conditions: Adsorbent dosage $6 \mathrm{~g} / \mathrm{L}$, temp. $25^{\circ} \mathrm{C}$, time $\left.24 \mathrm{hrs}, \mathrm{pH}=7.0 \pm 0.02\right)$.

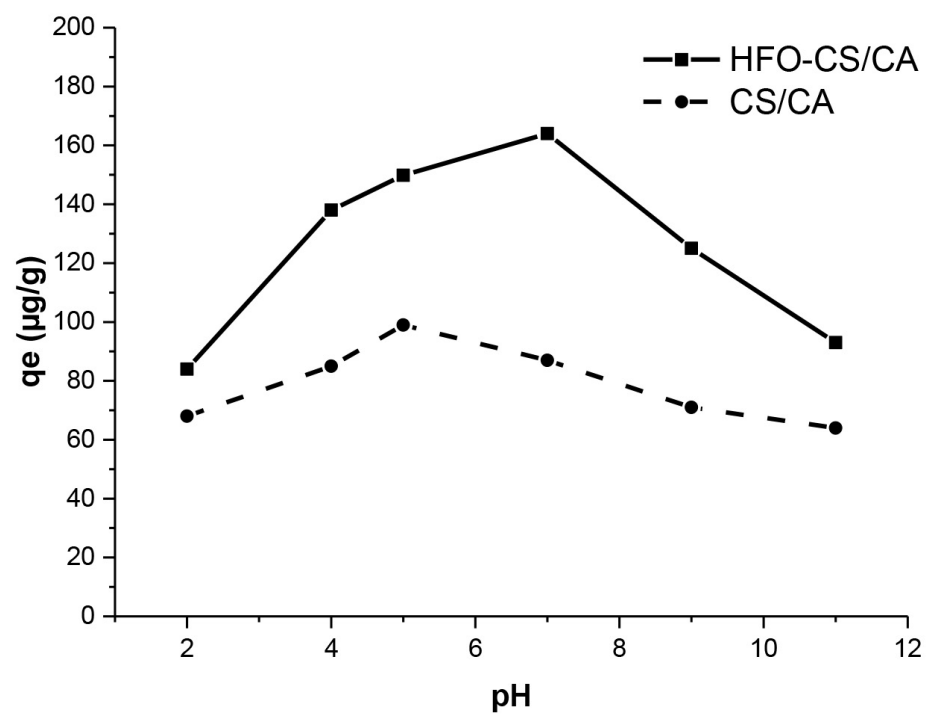

Figure 14. Effect of $\mathrm{pH}$ on adsorption capacity of phosphates (Adsorption conditions: $\mathrm{Co}=1.2 \mathrm{mgP} / \mathrm{L}$, adsorbent dosage $6 \mathrm{~g} / \mathrm{L}$, temp. $25^{\circ} \mathrm{C}$, time $24 \mathrm{hrs})$.

There is a varied distribution of phosphate species in deionized water at variable $\mathrm{pH}$ similar to other studies [7].

The effect of adsorption of phosphate ions on the HFO-CS/CA and CS/CA adsorbent could be explained by the electrostatic attraction between the adsorbate and adsorbent. The amine group in the adsorbent interacts with the dihydrogen and monohydrogen phosphate ions in $\mathrm{pH}$ range of 6.5 - 8. The protonated amine groups $\left(\mathrm{R}^{-} \mathrm{NH}^{3+}\right)$ on the surface of chitosan beads decrease with increasing $\mathrm{pH}$ as shown in Figure 15. Figure 16 shows the speciation curve of the hydrated iron oxides. 


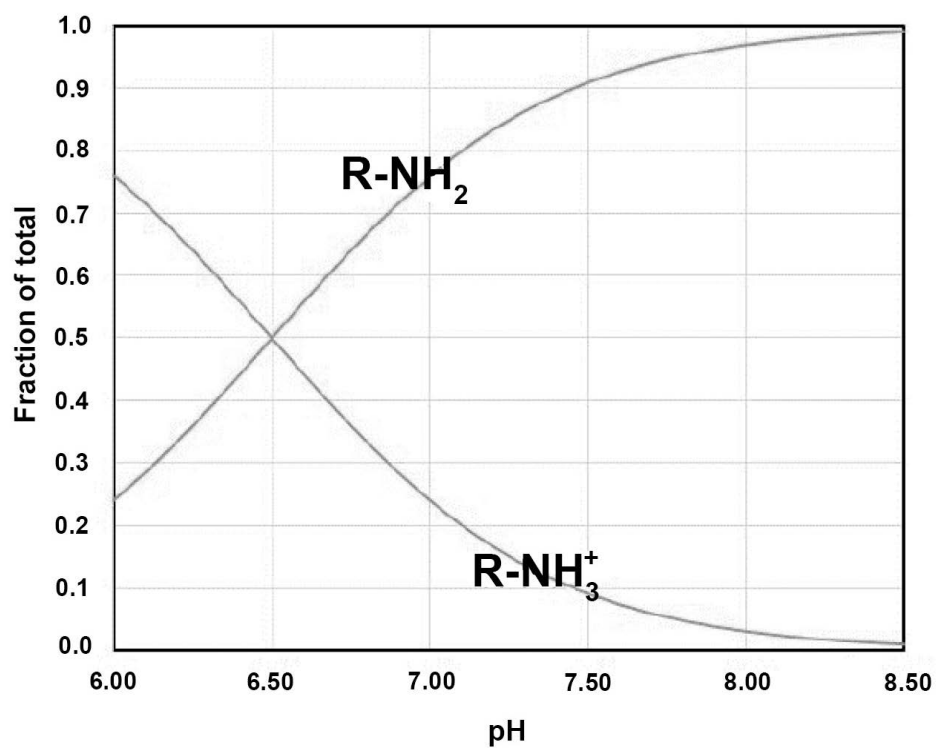

Figure 15. Speciation curve of Chitosan at different $\mathrm{pH}$ at $25^{\circ} \mathrm{C}$.

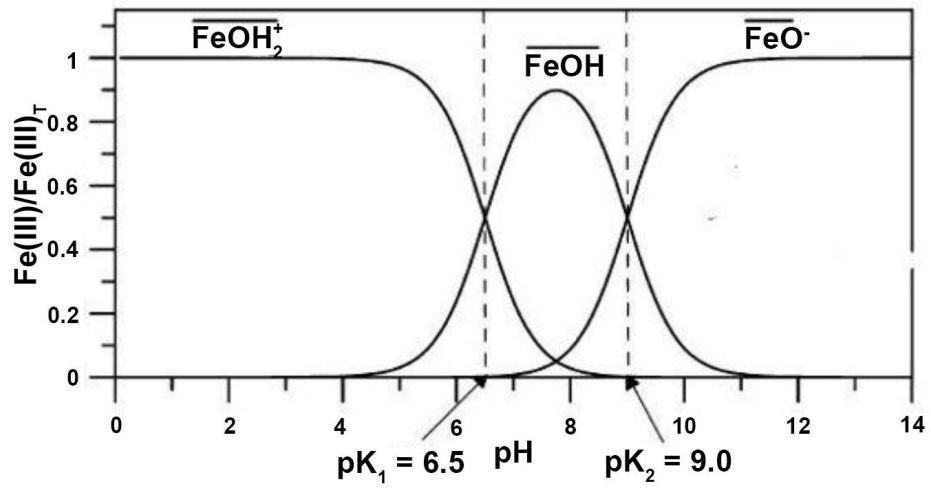

Figure 16. Speciation curve of hydrated iron oxides, at different $\mathrm{pH}$ at $25^{\circ} \mathrm{C}$.

The change in adsorption characteristics with $\mathrm{pH}$ may be explained with the acid-base properties of the chitosan based particles.

$$
\begin{gathered}
-\mathrm{NH}_{2}+\mathrm{H}^{+}-\mathrm{NH}_{3}^{+} \\
-\mathrm{NH}_{3}^{+}+\mathrm{H}_{2} \mathrm{PO}_{4}^{-}-\mathrm{NH}_{3} \mathrm{H}_{2} \mathrm{PO}_{4} \\
-\mathrm{NH}_{2}+\mathrm{OH}^{-}-\mathrm{NH}_{2} \mathrm{OH}^{-}
\end{gathered}
$$

The HFO-CS/CA beads had a greater adsorption capacity and removal efficiency as compared to the CS/CA beads. It means the HFO improved the performance of the chitosan based material. At high alkaline $\mathrm{pH}$ the hydrated iron oxides are highly negatively charged as in Figure 16, and Equation (3.3) above, resulting in repulsion of the negatively charged ions. And therefore the Donnan co-ion effect with the negatively charged phosphates is unfavourable. At around neutral $\mathrm{pH}$, there is formation of inner sphere complexes between the phosphate anions and the hydrated iron cations. Therefore the anions are trapped in the solid phase. At higher $\mathrm{pH}$, the hydrated irons are deprotonated and hence nega- 
tively charged and so are the phosphates and hence there is no possible electrostatic attraction of the species. Therefore adsorption of phosphate reduces.

The point of zero charge estimated using the zeta potential measurements was found to be around $\mathrm{pH}=6.2$ and $\mathrm{pH}=5.4$ for the HFO-CS/CA and CS/CA bead materials respectively, as in Figure 17. For both materials, the surface is positively charged at lower $\mathrm{pH}$ values. The results were similar to other studies done on phosphate adsorption [7] [19] [20].

\subsubsection{Effect of Temperature}

The adsorption capacity of HFO-CS/CA beads was studied at different temperatures at $15^{\circ} \mathrm{C}, 25^{\circ} \mathrm{C}, 35^{\circ} \mathrm{C}$ and $50^{\circ} \mathrm{C}$. The adsorption capacity increased with an increase in temperature although with very small margins as shown in Figure 18.

This cannot be used to conclude whether phosphate uptake on the iron oxide loaded CS/CA beads is endothermic, an entropy test needs to be performed. However, this can be attributed to the fact that at higher temperatures there is an acceleration of diffusion of phosphate ions into the adsorbent, and also an enlargement of the pore size of adsorbent to some extent.

\subsection{Effect of Competing Ions}

Figure 19 shows the results obtained of the adsorption capacity when $\mathrm{Cl}^{-}$, $\mathrm{SO}_{4}^{2-}, \mathrm{CO}_{3}^{2-}$ and $\mathrm{NO}_{3}^{-}$anions were present in the solution. It was observed the anions influenced the adsorption of phosphate with $\mathrm{Cl}^{-}$and $\mathrm{NO}_{3}^{-}$ions showing only slight reduction while $\mathrm{SO}_{4}^{2-}$ and $\mathrm{CO}_{3}^{2-}$ ions had a bigger effect. This can be explained by the fact that $\mathrm{SO}_{4}^{2-}$ and $\mathrm{CO}_{3}^{2-}$ ions form both inner and outer spheres complexes [21] [22], with the active sites similar to those of phosphates, whereas $\mathrm{Cl}^{-}$and $\mathrm{NO}_{3}^{-}$ions form weaker bonds of outer complexes [21]. These surface complexes reduce the active sites inhibiting the adsorption of

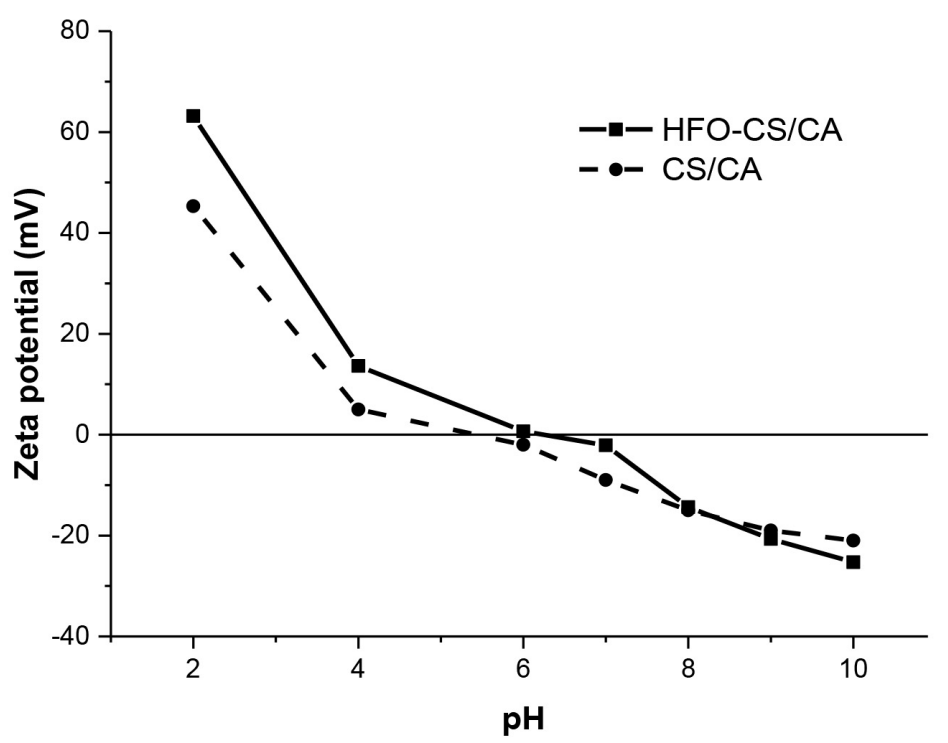

Figure 17. Zeta potential of HFO-CS/CA material. 


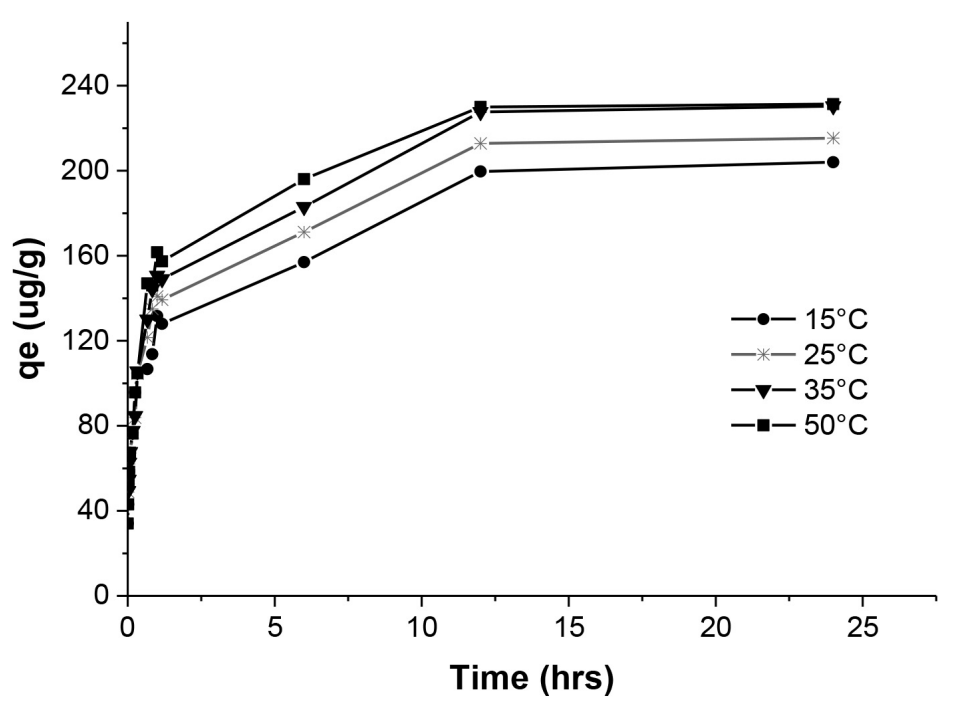

Figure 18. Effect of temperature on adsorption capacity of phosphates (Adsorption conditions: $\mathrm{Co}=1.2 \mathrm{mgP} / \mathrm{L}$, adsorbent dosage $6 \mathrm{~g} / \mathrm{L}, \mathrm{pH}=7.0$ $\pm 0.02)$.

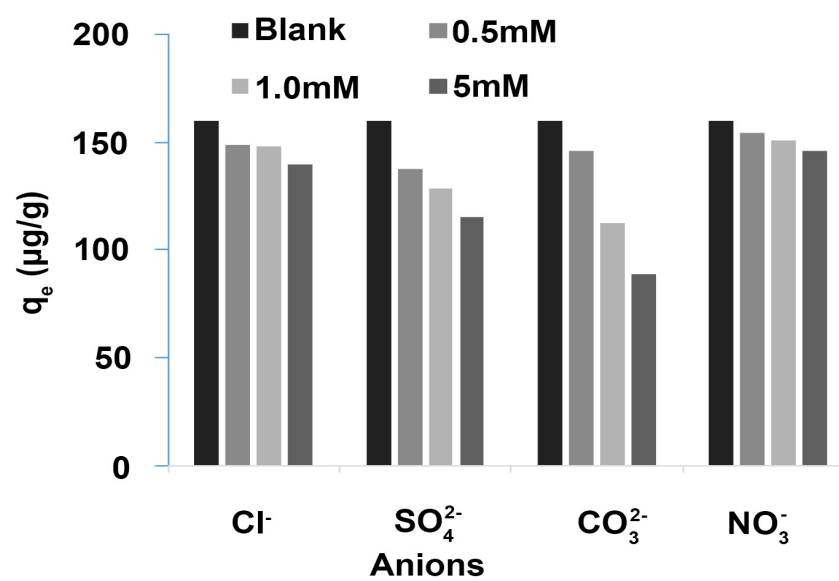

Figure 19. Column graph showing effect of coexisting ions on adsorption capacity of phosphates, at different anion concentrations (Adsorption conditions: $\mathrm{Co}=1.2 \mathrm{mgP} / \mathrm{L}$, adsorbent dosage $6 \mathrm{~g} / \mathrm{L}$, temp. $25^{\circ} \mathrm{C}$, time $24 \mathrm{hrs}, \mathrm{pH}=7.0 \pm 0.02$ ).

phosphates. Furthermore, $\mathrm{SO}_{4}^{2-}$ and $\mathrm{CO}_{3}^{2-}$ may accumulate on or near the surface of the adsorbent forming negatively charged surfaces which results in repulsion forces with the phosphate anions. Increasing the concentration of the $\mathrm{Cl}^{-}, \mathrm{SO}_{4}^{2-}, \mathrm{CO}_{3}^{2-}$ and $\mathrm{NO}_{3}^{-}$anions, from $0.5 \mathrm{mM}$ to $5 \mathrm{mM}$ caused a further reduction in the adsorption capacity.

\subsection{Adsorption Kinetics}

Kinetic models were used to investigate the mechanism of adsorption and its potential rate controlling steps for HFO-CS/CA beads. The maximum rate of increase on adsorption capacity was observed in the first 1 hour of the experiment. The kinetic models used were grouped into two; adsorption reaction 
models namely the Pseudo First order model (Lagergren model), the Pseudo Second order model (Ho and McKay Model), and Elovich model, and the Adsorption diffusion models namely the Intra-particle diffusion model (Weber and Morris model).

Pseudo First Order Model: The Lagergren's first order equation was used. It is widely used for adsorption of adsorbate from an aqueous solution, and is represented as,

$$
\ln (q e-q t)=\ln q e-K 1 t
$$

where, $q e$ is the equilibrium adsorption capacity $(\mathrm{mg} / \mathrm{g}), q t$ is the adsorption capacity at time $t(\mathrm{mg} / \mathrm{g}), K 1$ is the first order rate constant, $\left(\mathrm{min}^{-1}\right)$. The pseudo first order considers that the rate at which the adsorption sites are occupied by the adsorbate is directly proportional to the number of unoccupied sites. A plot of $\ln (q e-q t)$ vs. $t$ is used to give a linear relationship for the applicability of the first order kinetic. The slope of the graph gives the value of $K 1$ and the $y$-intercept gives the value of qe. Figure 20 represents the Pseudo First Order sorption kinetics of phosphate anions on to the iron oxide loaded chitosan-cellulose acetate particles, at various temperatures $50^{\circ} \mathrm{C}, 35^{\circ} \mathrm{C}, 25^{\circ} \mathrm{C}$ and $15^{\circ} \mathrm{C}$ with an adsorbent dosage of $6 \mathrm{~g} / \mathrm{L}$, initial phosphate concentration of 2.0 $\mathrm{mg} / \mathrm{l}$ and $\mathrm{pH} 7.0 \pm 0.2$.

Pseudo Second Order Model: This model considers that the rate of adsorption of ions is based on the square of number of vacant sites on the adsorbent. It is represented by the equation below as,

$$
t / q t=1 /(K 2 q e 2)+t / q e
$$

A plot of $t / q t$ vs $t$ should give a linear relationship for the applicability of the second order kinetics. The slope of the graph gives the value of $1 /$ qe while the value of $K 2$ rate constant of pseudo second order adsorption, $\mathrm{g}\left(\mathrm{mg}^{-1} \cdot \mathrm{min}^{-1}\right)$, can be calculated from the y-intercept. Figure 21 represents the Pseudo Second

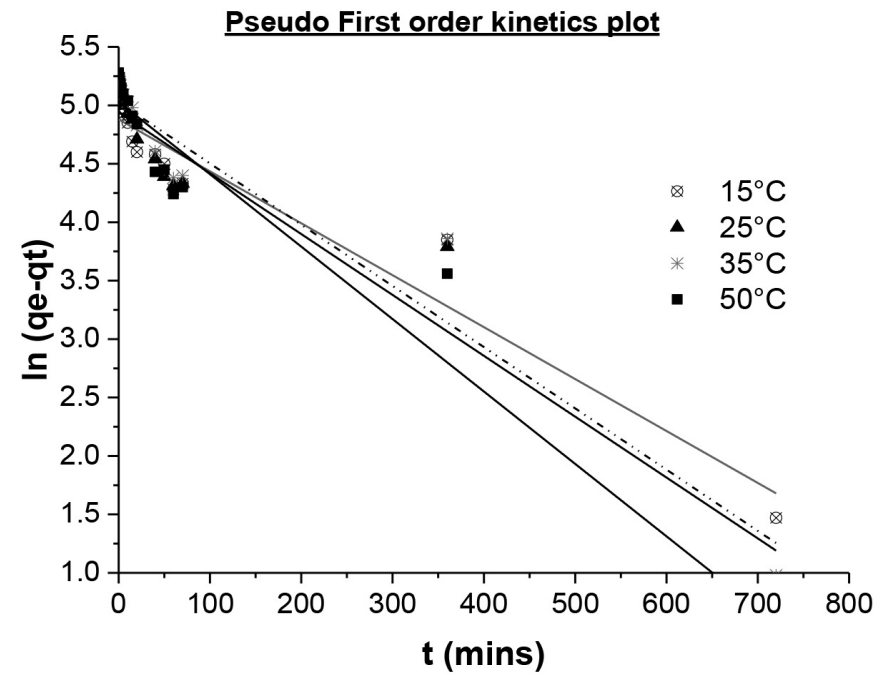

Figure 20. Pseudo First order kinetic plot for the adsorption of phosphate ions onto HFO-CS/CA particles at different temperature. 


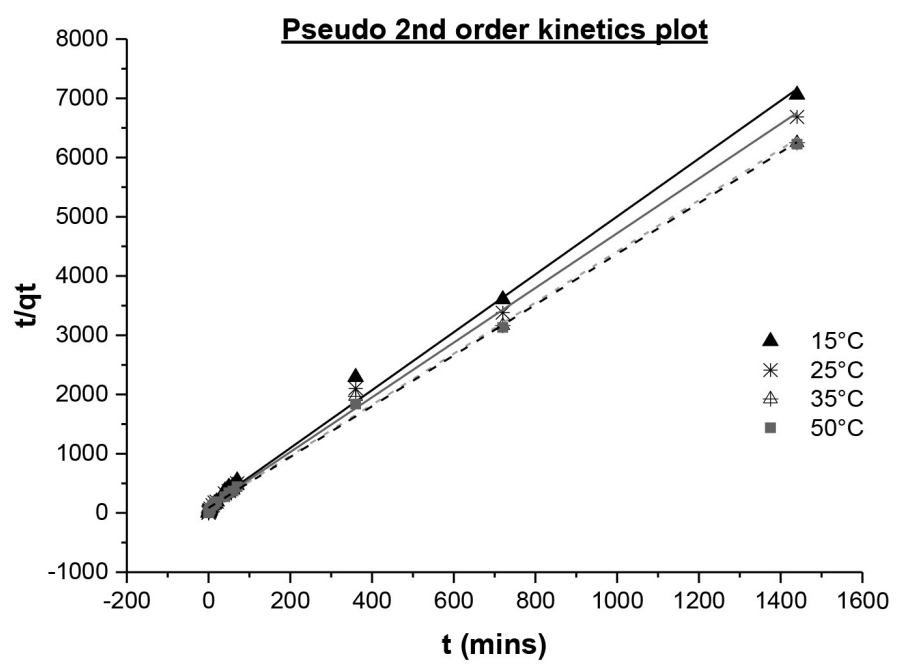

Figure 21. Pseudo Second order kinetic plot for the adsorption of phosphate ions onto IO-CS/CA particles at different temperature.

Order sorption kinetics of phosphate anions on to the iron oxide loaded chitosan-cellulose acetate particles, at various temperatures $50^{\circ} \mathrm{C}, 35^{\circ} \mathrm{C}, 25^{\circ} \mathrm{C}$ and $15^{\circ} \mathrm{C}$ with an adsorbent dosage of $6 \mathrm{~g} / \mathrm{L}$, initial phosphate concentration of 2.0 $\mathrm{mg} / \mathrm{Land} \mathrm{pH} 7.0 \pm 0.2$.

Simple Elovich model: The Elovich equation has been widely used in adsorption kinetics which describes chemical adsorption (chemical reaction) mechanism in nature [23]. The Elovich model describes the adsorption of gas on to solid systems. It has also been applied in the adsorption of ions from aqueous solutions. The simple Elovich model is expressed as,

$$
q t=\ln a b b+1 b \ln t
$$

The parameter $a$ is the initial adsorption rate, $\mathrm{mg}\left(\mathrm{g}^{-1} \cdot \mathrm{min}^{-1}\right)$, and $b$ is related to extent of surface coverage and activation energy for chemisorption, $\mathrm{g} \cdot \mathrm{mg}^{-1}$.

The equation can be simplified as;

$$
q t=\alpha+\beta \ln t
$$

where $\alpha$ and $\beta$ are constants obtained from the experiment. A plot of $q t$ vs. $\ln t$ should give a linear relationship for the applicability of the simple Elovich kinetic. The value of $\alpha$ was calculated from the y-intercept, and $\beta$ from the slope. Figure 22 represents the Simple Elovich model sorption kinetics of phosphate anions on to the iron oxide loaded chitosan-cellulose acetate particles, at various temperatures $50^{\circ} \mathrm{C}, 35^{\circ} \mathrm{C}, 25^{\circ} \mathrm{C}$ and $15^{\circ} \mathrm{C}$ with an adsorbent dosage of $6 \mathrm{~g} / \mathrm{l}$, initial phosphate concentration of $2.0 \mathrm{mg} / \mathrm{l}$ and $\mathrm{pH} 7.0 \pm 0.2$. Good correlation of the Elovich model with the experimental data indicates heterogeneous adsorption behaviour that concurs with the nature of chemical adsorption.

The parameters of First order, Second order and Simple Elovich kinetics model for the adsorption of phosphate ions by the Iron oxide loaded chitosan-cellulose acetate particles were calculated from the linear fits of the various curves, and tabulated in Table 1. 


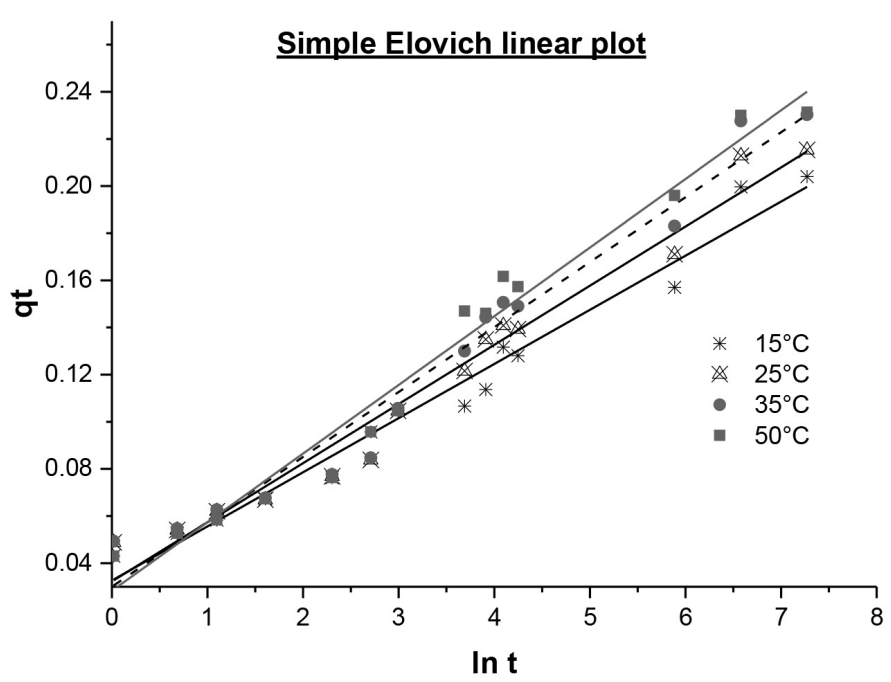

Figure 22. Simple Elovich liner plot for the adsorption of phosphate ions onto IO-CS/CA particles at different temperature.

Table 1. Estimated parameters of kinetic models for the adsorption of phosphates by Iron oxide loaded Chitosan-cellulose acetate particles.

\begin{tabular}{ccccccccc}
\hline & & \multicolumn{2}{c}{$\begin{array}{c}\text { First Order Kinetic } \\
\text { Model }\end{array}$} & \multicolumn{2}{c}{$\begin{array}{c}\text { Second Order } \\
\text { Kinetic Model }\end{array}$} & \multicolumn{4}{c}{$\begin{array}{c}\text { Elovich Kinetic } \\
\text { Model }\end{array}$} \\
\cline { 3 - 8 } Temp. ${ }^{\circ} \mathrm{C}$ & Expe. $q_{e}$ & \multicolumn{1}{c}{$\mathrm{R}^{2} \times 10^{-1}$} & $q_{e} \mathrm{mg} / \mathrm{g}$ & $\mathrm{R}^{2} \times 10^{-1}$ & $q_{e} \mathrm{mg} / \mathrm{g}$ & $\mathrm{R}^{2}$ & $\begin{array}{c}\alpha \\
(\mathrm{mg} /(\mathrm{gmin}))\end{array}$ & $\begin{array}{c}\beta \\
(\mathrm{g} / \mathrm{mg}) \\
\times 10^{-2}\end{array}$ \\
\hline $\mathbf{1 5}$ & 0.20 & 9.2 & 0.13 & 9.95 & 0.20 & 0.97 & 0.03 & 2.3 \\
$\mathbf{2 5}$ & 0.21 & 9.2 & 0.14 & 9.96 & 0.21 & 0.96 & 0.03 & 2.5 \\
$\mathbf{3 5}$ & 0.23 & 9.3 & 0.15 & 9.96 & 0.23 & 0.96 & 0.03 & 2.8 \\
$\mathbf{5 0}$ & 0.23 & 9.3 & 0.15 & 9.98 & 0.23 & 0.97 & 0.02 & 2.9 \\
\hline
\end{tabular}

The linear regression $\left(\mathrm{R}^{2}\right)$ values of the above three models were compared. The Pseudo first order kinetic model had the lowest values and hence the inapplicability of this model. The equilibrium adsorption capacity ( $q$ e) of the Pseudo first order kinetic model was also much contrasted from the experiment $q e$. The $\mathrm{R}^{2}$ values obtained from the Elovich model were also lower as compared to the Pseudo second order kinetic model. The $\mathrm{R}^{2}$ values in the Pseudo second order kinetic model were the highest $\left(\mathrm{R}^{2}>0.99\right)$ as seen in Table 1 , and the qe were very close to the experimental values. Therefore, the adsorption of phosphates by iron oxide loaded chitosan-cellulose acetate particles followed the pseudo second order kinetic model, and it suggests that chemisorption, involving valence shared or electron exchange between adsorbate and adsorbent is what the adsorption is based on [24]. Similar observations have also been report in other studies [15] [25] [26]. In general, the regression for all three models was found to be $\mathrm{R}^{2}>0.9$ and hence the results suggest both physical and chemical adsorption might be involved in the adsorption process.

Intra-Particle Diffusion Model (Weber-Morris): The intra-particle diffusion model (IPD) proposed by Weber and Morris has been widely applied for the 
analysis of adsorption kinetics. The model describes the sorption process from a mechanistic point of view. The overall sorption is described to occur in multiple steps. The adsorption mechanism occurs in three consecutive steps: mass transfer across the external film of liquid surrounding the particle, adsorption at the surface of pores and the intra-particle diffusion. The slowest of these steps determines the overall rate of process. In order to analyse the mechanism of the adsorption of phosphate anions by the iron oxide loaded chitosan-cellulose acetate particles, the experimental data was tested against the Intra-Particle Diffusion Model given by the equation;

$$
q t=K 3 t 0.5+I
$$

where $K 3$ is the intra-particle diffusion rate constant and $I$ is the y-intercept. A plot of $q t$ vs t0.5 was drawn to analyse the possibility of the intra-particle diffusion as the rate determining step. Figure 23 represents the intra-particle diffusion model sorption kinetics of phosphate anions on to the iron oxide loaded chitosan-cellulose acetate particles, at various temperatures $50^{\circ} \mathrm{C}, 35^{\circ} \mathrm{C}, 25^{\circ} \mathrm{C}$ and $15^{\circ} \mathrm{C}$ with an adsorbent dosage of $6 \mathrm{~g} / \mathrm{l}$, initial phosphate concentration of $2.0 \mathrm{mg} / \mathrm{l}$ and $\mathrm{pH} 7.0 \pm 0.2$.

Table 2 shows the parameters estimated from the intra-particle kinetic model.

The Intra-particle diffusion kinetic model is based on the Weber-Morris theory that proposed that if the relationship is linear and it passes through the origin, then the adsorption process was controlled by the intra-particle diffusion only. However, results in Table 2 show the relationship was linear but the lines did not pass through the origin. Therefore intra-particle diffusion was involved but it wasn't the only limiting factor. It has also been noted in other studies [15] [27], that the adsorption of phosphate occurs first by the physical diffusion of phosphate in solution in the liquid film surrounding the particles, and within the pores of IO-CS/CA particles, followed by a chemical reaction between the

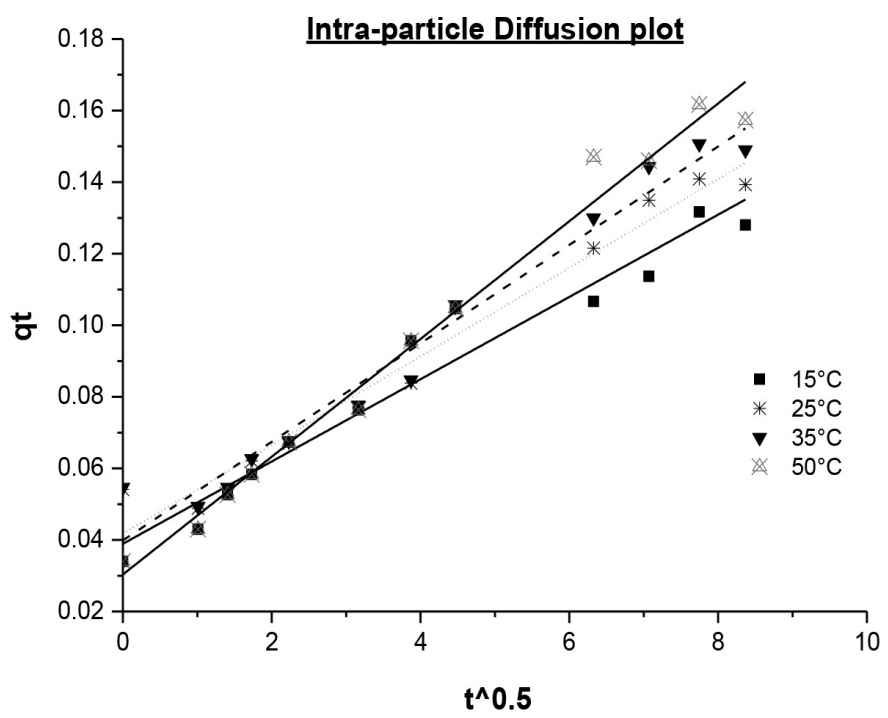

Figure 23. Intra-particle diffusion plot for the adsorption of phosphate ions onto HFO-CS/CA particles at different temperature. 
Table 2. Estimated parameters of Intra-particle diffusion kinetic models for the adsorption of phosphates by Iron oxide loaded Chitosan-cellulose acetate particles.

\begin{tabular}{ccccc}
\hline & & \multicolumn{3}{c}{ Intra-particle diffusion model } \\
\cline { 3 - 5 } Temp. ${ }^{\circ} \mathrm{C}$ & Expe. $q_{e}$ & $\mathrm{R}^{2}$ & $K 3\left(\mathrm{gmg}^{-1} \cdot \mathrm{min}^{-1}\right)$ & $I$ (Intercept) \\
\hline 15 & 0.204 & 0.948 & 0.012 & 0.039 \\
25 & 0.215 & 0.968 & 0.012 & 0.042 \\
35 & 0.230 & 0.968 & 0.014 & 0.040 \\
50 & 0.231 & 0.980 & 0.016 & 0.030 \\
\hline
\end{tabular}

phosphate species and the IO-CS/CA. From the intra-particle diffusion kinetic model, the linear regression values increased with an increase in temperature. Non-zero intercept indicates boundary layer diffusion-rate limiting step [26] [27] [28].

\subsection{Adsorption Isotherms}

The adsorption isotherms were used to describe the interaction of adsorbate with adsorbent. They relate the amount of adsorbate on an adsorbent as a function of pressure or concentration for gases and liquids respectively, at a constant temperature. The experimental adsorption data for adsorption of phosphate anions by iron oxide loaded chitosan-cellulose acetate particles was analysed by Freundlich and Langmuir isotherm models.

Freundlich Isotherm: The experimental data were analysed by Freundlich Isotherm model using the equation form,

$$
q e=K_{f} C e 1 / n
$$

where $q e$ is the adsorption capacity at equilibrium $(\mathrm{mg} / \mathrm{g}), C e$ is the liquid phase adsorbate concentration at equilibrium $(\mathrm{mg} / \mathrm{L}) K_{f}$ is the Freundlich constant $(\mathrm{mg} / \mathrm{g})$ and $\mathrm{n}$ is the heterogeneity factor which is related to adsorption intensity or surface heterogeneity. A plot of $q e$ vs. Ce was used to model the Freundlich isotherm. The $K_{f}$ was calculated from the slope. This is shown in Figure 24.

Langmuir Isotherm: The experimental data was also analysed by Langmuir Isotherm model using the equation form,

$$
q_{e}=Q_{m} K C e 1+K C e
$$

where, $Q_{m}$ is the maximum mass adsorbed at saturation conditions per unit mass of adsorbent $(\mathrm{mg} / \mathrm{g})$ and $K$ is the empirical constant between the sorbate and sorbent, also known as the Langmuir affinity coefficient (L/mg). A plot of $q e$ vs. $C e$ was used to model the Langmuir isotherm. $Q_{m}$ and $K$ were calculated from the graphs. This is shown in Figure 25.

The estimated values of the constants of the Freundlich and Langmuir Isotherm models for the adsorption of phosphate anions on to the iron oxide loaded chitosan-cellulose acetate particles are shown below.

The $K_{f}$ is the Freundlich adsorption constant, as earlier noted, and it is the maximum adsorption capacity $(\mathrm{mg} / \mathrm{g}$ ) of ions while $n$ is a dimensionless constant 


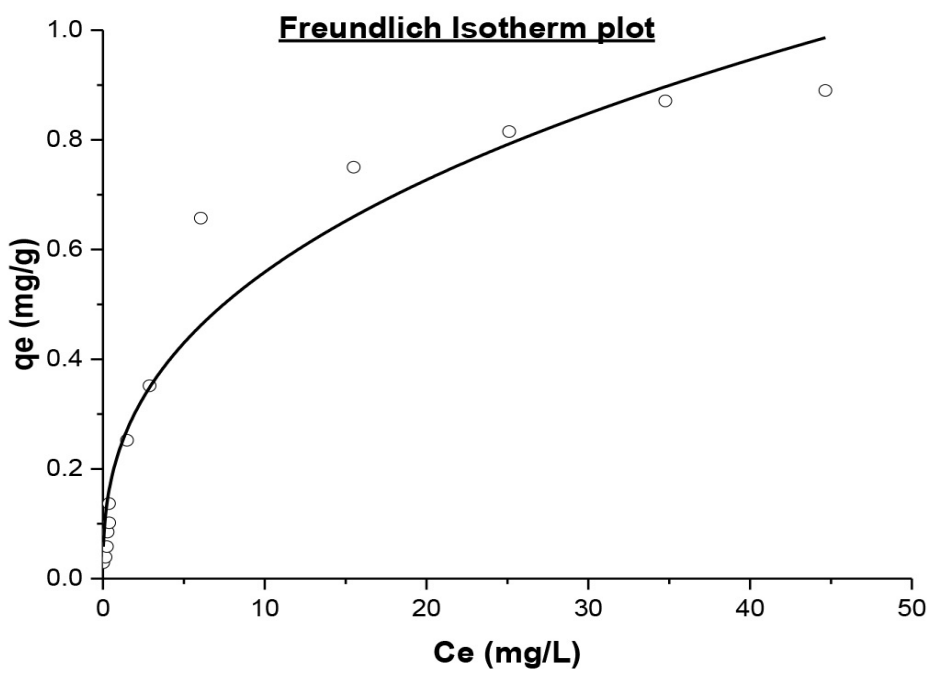

Figure 24. Non-linear fit of Freundlich Isotherm model for the adsorption of phosphate ions onto HFOCS/CA particles at $25^{\circ} \mathrm{C}, \mathrm{pH} 7.0 \pm 0.2$, adsorbent dosage of $6 \mathrm{~g} / \mathrm{l}$ and varying initial concentration of phosphate.

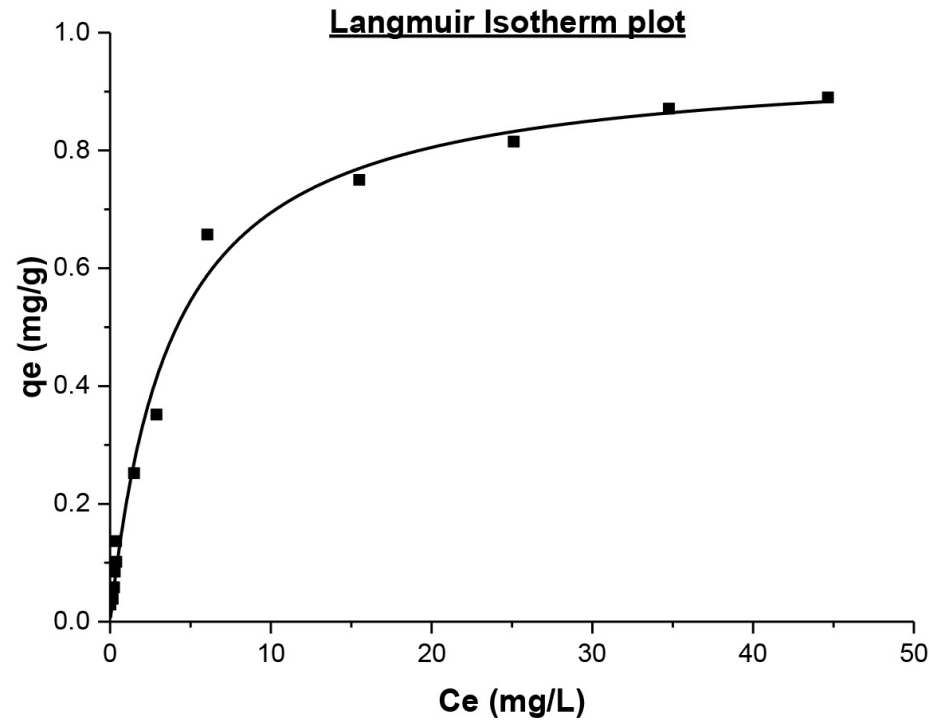

Figure 25. Non-linear fit of Langmuir Isotherm model for the adsorption of phosphate ions onto HFOCS/CA particles at $25^{\circ} \mathrm{C}, \mathrm{pH} 7.0 \pm 0.2$, adsorbent dosage of $6 \mathrm{~g} / \mathrm{l}$ and varying initial concentration of phosphate.

that illustrates the adsorption intensity. Based on the correlation coefficients $\left(\mathrm{R}^{2}\right.$ values) in Table 3, $\mathrm{R}^{2}=0.99$ shows goodness of fit for the Langmuir model. The Langmuir model is based on the assumption that maximum adsorption corresponds to monolayer saturation of the adsorbent surface, with no lateral interaction between the adsorbed molecules. The Langmuir model showed a maximum $q e$ of $0.958 \mathrm{mg} / \mathrm{g}$. On the other hand, the correlation coefficient of the Freundlich model was lower than that of Langmuir, though still considerable because $\mathrm{R}^{2}>0.9$. A good fit to the Freundlich model shows a multilayer adsorption with non-uniform distribution of adsorption of heat and affinities over the 
Table 3. Estimated values of the constants of the Freundlich and Langmuir Isotherm models.

\begin{tabular}{cccccc}
\hline & \multicolumn{3}{c}{ Freundlich Isotherm } & \multicolumn{3}{c}{ Langmuir Isotherm } \\
\hline $\mathrm{R}^{2}$ & $K_{f}(\mathrm{mg} / \mathrm{g})$ & $1 / \mathrm{n}$ & $\mathrm{R}^{2}$ & $q_{\max }(\mathrm{mg} / \mathrm{g})$ & $K(\mathrm{~L} / \mathrm{mg})$ \\
\hline 0.94 & 0.233 & 0.379 & 0.99 & 0.958 & 0.263 \\
\hline
\end{tabular}

heterogeneous surface [29]. The $K_{f}$ from the curve gave $0.233 \mathrm{mg} / \mathrm{g}$ as the maximum adsorption capacity of the HFO-CS/CA, and an adsorption intensity of $\mathrm{n}=2.64$. For this study, Langmuir Isotherm was more suited. The adsorption affinity decreased exponentially as amount of adsorption increased, and that adsorption is not monolayer singularly monolayer. The close conformity to Freundlich model suggests presence of multiple sites for sorption.

\subsection{Regeneration Studies}

Test results showed that $10 \% \mathrm{NaCl}$ solution had a better eluting effect than $\mathrm{M}$ $\mathrm{NaOH}$. The second adsorption cycle, bead material that had been regenerate using $10 \% \mathrm{NaCl}$ had a removal efficiency of about $88.57 \%$ compared to that of $1 \mathrm{M}$ $\mathrm{NaOH}$ at $77.56 \%$. On the third cycle the efficiency of beads regenerate with $1 \mathrm{M}$ $\mathrm{NaOH}$ greatly reduced to about $44 \%$ as compared to that of $10 \% \mathrm{NaCl}$ which was still above $80 \%$. Figure 26 shows the comparison of the four tests methods done on the regeneration studies. This shows that the $\mathrm{NaCl}$ (aq) moderate ionic strength was an efficient method for removal of the adsorbed phosphate, and the $\mathrm{Cl}^{-}$ions could be responsible for ion exchange. $1 \mathrm{M} \mathrm{NaOH}$ solution also had a considerable desorption potential, and the removal efficiency was enhanced by rinsing with $\mathrm{HCl}$ acid (of about $\mathrm{pH}=4.0$ ) before next adsorption cycle. $\mathrm{HCl}$ lowered the $\mathrm{pH}$ of the bead system because as earlier discussed high $\mathrm{pH}$ values cause deprotonated and negatively charged HFO-CS/CA bead system. For each cycle, the removal efficiency was above $60 \%$ in all the five rounds when using $10 \% \mathrm{NaCl}$. Another observation was that there is no need to rinse the beads with $\mathrm{HCl}$ after using $\mathrm{NaCl}$ for desorption. These results confirm to other studies done [7], which show $\mathrm{NaCl}$ has good desorption properties. This is a versatile method for the regeneration of HFO-CS/CA bead system.

\section{Conclusion}

Phosphates contamination of various water resources is of great concern because of the eutrophication effect in aquatic environments. Hydrated Iron oxides loaded chitosan-cellulose acetate (HFO-CS/CA) adsorbent was tested for its improved adsorption capacity, compared to chitosan-cellulose acetate (CS/CA) adsorbent. From the experimental results and analysis, it is concluded that adsorption process offers the potential of phosphates removal from water during the tertiary water treatment. Adsorption facilities are the solution to provide low capital costs systems that require minimal space and energy for water treatment. The effects of the various conditions for phosphate adsorption are investigated 


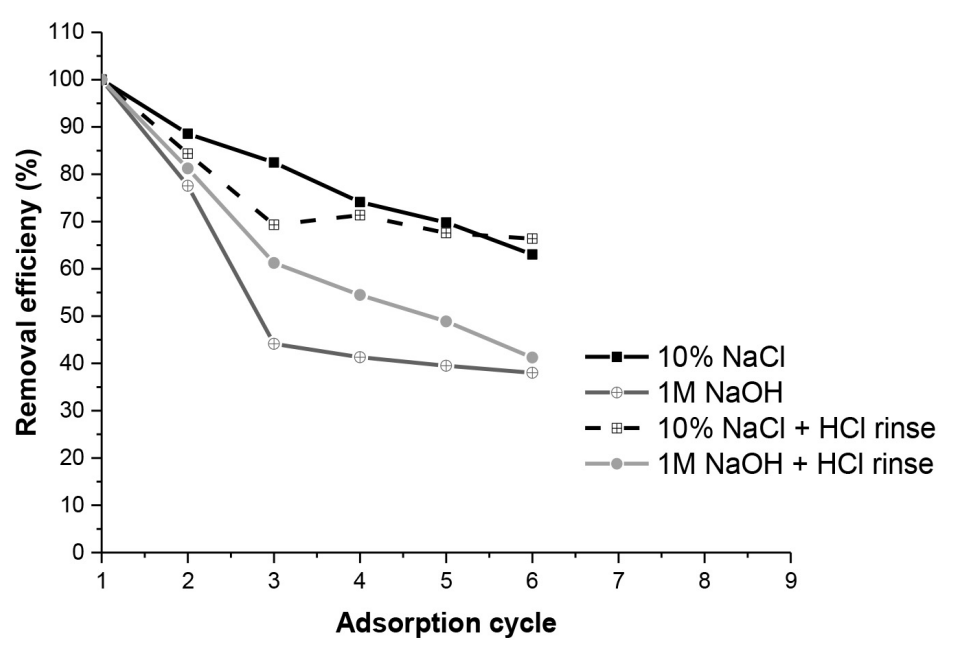

Figure 26. The removal efficiency for different adsorption cycles after desorption using various solutions.

systematically. The optimum conditions were thus obtained. It was concluded that maximum phosphate adsorption occurs at lower $\mathrm{pH}$ of about $5.5-6.5$, and the equilibrium contact time was established to be $24 \mathrm{hrs}$ for this material. The experimental data were well fitted to the pseudo second order model as well as the Langmuir isotherm model with a maximum adsorption of $958 \mu \mathrm{g} / \mathrm{g}$. The Freundlich isotherm model also had a close fit with a maximum adsorption of $233 \mu \mathrm{g} / \mathrm{g}$, which was very close to the experimental maximum adsorption. This suggested presence of multilayer adsorption attributed to the iron loading. Temperature studies show no significant difference; the slight increase however reveals that the nature of adsorption is endothermic. SEM images show the macroporous structure of the chitosan-based adsorbents. The FT-IR, XRD, XPS and zeta potential studies show that the adsorption mechanism is both by ion exchange mechanism and electrostatic attraction between the phosphate ions and HFO-CS/CA beads. The amine groups and the ferric are the main binding sites for phosphate adsorption, forming surface complexes during the adsorption. Regeneration studies show that the adsorbent could be re-used a number of times before an environmentally friendly disposal method is employed. In the study, it was re-used for up to five times and the removal efficiency was above $60 \%$ in all the rounds.

\section{Acknowledgements}

This study was supported by the Ministry of Commerce of People's Republic of China, and the Suzhou University of Science and Technology. The support is much acknowledged.

\section{Conflicts of Interest}

The authors declare no conflicts of interest regarding the publication of this paper. 


\section{References}

[1] US Department of Health and Human Services (2017) Center for Disease Control and Prevention United States.

https://www.cdc.gov/nceh/clusters/fallon/organophosfaq.htm

[2] Khan, M., Nasir, K. and Mohammad, F. (2014) Eutrophication of Lakes: Eutrophication Causes, Consequences and Control. Science and Business Media, Berlin, Heidelberg, 978-981.

[3] Thomas, D. and Leopold, L.B. (1978) Water in Environmental Planning. W.H. Freeman Publishers, New York.

[4] Chester, D.R. (1989) Groundwater Contamination: Sources, Control, and Preventative Measures. Technomic Publishing Co. Inc., Lancaster.

[5] Gray, N.F. (2005) Water Technology. Elsevier Butterworth Heinemann, Oxford.

[6] Tchobanoglous, G. and Burton, F.L. (1991) Wastewater Engineering-Treatment, Disposal and Reuse. McGraw Hill, Pennsylvania, PA.

[7] Mohamed, M.H. and Wilson, L.D. (2015) Cross-Linked Chitosan Beads for Phopshate Removal from Aqueous Solution. Water Science and Technology, 61, 497-505.

[8] Bernades, A.M. and Rodrigues, M. (2014) Electrodialysis and Water Reuse: Novel Approaches. Journal of Chemistry Analysis, 99, 63-75.

[9] Metcalf, E. (2003) Wastewater Engineering: Treatment and Reuse. 4th Edition, McGraw Hill, Pennsylvania, PA.

[10] Leon, C.O., Lee, D.S. and Park, J.M. (2000) Morphological Characteristics of Microbial Sludge Performing Enhanced Biological Phosphorous Removal in a Sequencing Batch Reactor Fed with Glucose as Sole Carbon Source. Water Science and Technology, 41, 79-84. https://doi.org/10.2166/wst.2000.0245

[11] Nan, L. and Renbi, B. (2005) Copper Adsorption on Chitosan-Cellulose Hydrogel Beads: Behaviors and Mechanisms. Separation and Purification Technology, 42, 237-247. https://doi.org/10.1016/j.seppur.2004.08.002

[12] Li, N., Bai, R. and Liu, C. (2005) Enhanced and Selective Adsorption of Mercury Ions on Chitosan Beads Grafted with Polyacrylamide via Surface-Initiated Atom Transfer Radical Polymerization. Langmuir, 21, 11780-11787. https://doi.org/10.1021/la051551b

[13] Casey, L.S. and Wilson, L.D. (2015) Investigation of Chitosan-PVA Composite Films and Their Adsorption Properties. Journal of Geoscience and Environment Protection, 3, 78-84. https://doi.org/10.4236/gep.2015.32013

[14] Luis, C. and Arup, K.S. (2005) Arsenic Removal Using Polymer-Supported Hydrate Iron (III) Oxide Nanoparticles: Role of the Donnan Membrane Effect. Environmental Science and Technology, 39, 6508-6515.

https://doi.org/10.1021/es050175e

[15] Yang, M., Lin, J., Zhan, Y. and Zhang, H. (2014) Adsorption of Phosphate from Water on Lake Sediments Amended with Zirconium-Modified Zeolites in Batch Mode. Ecological Engineering, 71, 223-233. https://doi.org/10.1016/j.ecoleng.2014.07.035

[16] Sowmya, A. and Meenakshi, S. (2014) Zr(IV) loaded Cross-Linked Chitosan Beads with Enhanced Surface Area for the Removal of Nitrate and Phosphate. International Journal of Biological Macromolecules, 69, 336-343. https://doi.org/10.1016/j.ijbiomac.2014.05.043

[17] Moganavally, P. and Deepa, M. (2016) Adsorptive Removal of Lead and Cadmium 
Ions using Cross-Linked CMC Schiff Base: Isotherm, Kinetics and Catalytic Activity. Oriental Journal of Chemistry, 32, 441-453.

https://doi.org/10.13005/ojc/320150

[18] Cullity, B.D. (2001) Elements of X-Ray Diffraction. 3rd Edition, Pearson Publishers, London.

[19] Zhang, H.L., et al. (2013) Phosphorous Removal in an Enhanced Biological Phosphorous Removal Process: Roles of Extracellular Polymeric Substances. Environmental Science and Technology, 47, 1142-1148. https://doi.org/10.1021/es403227p

[20] Binjun, P., et al. (2009) Development of Polymer Based Nanosized Hydrated Ferric oxides (HFOs) for Enhanced Phosphate Removal from Waste Effluent. Water Research Journal, 43, 4421-4429. https://doi.org/10.1016/j.watres.2009.06.055

[21] Khare, N., Hesterberg, D. and Martin, J.D. (2005) XANES Investigation of Phosphate Sorption in Single and Binary Systems of Iron and Aluminium Oxide Minerals. Environmental Science and Technology, 39, 2152-2160. https://doi.org/10.1021/es049237b

[22] Lefevre, G. (2004) In Situ Fourier Transform Infrared Spectroscopy Studies of Inorganic Ions Adsorption on Metal Oxides and Hydroxides. Advances in Colloid and Interface Science, 107, 109-123. https://doi.org/10.1016/j.cis.2003.11.002

[23] Feng, C.W., Ru, L.T. and Ruey, S.J. (2009) Characteristics of Elovich Equation Used for the Analysis of Adsorption Kinetics in Dye-Chitosan System. Chemical Engineering Journal, 150, 366-373. https://doi.org/10.1016/j.cej.2009.01.014

[24] Rudzinski, W. and Plazinski, W. (2009) The Applicability of the Pseudo-Second Order Equation to Represent the Kinetics of Adsorption at Solid/Solution Interfaces: A Theoretical Analysis Based on the Statistical Rate Theory. Adsorption Journal, 15, 181-192. https://doi.org/10.1007/s10450-009-9167-8

[25] Yang, M., Lin, J., Zhan, Y., Zhu, Z. and Zhang, H. (2015) Immobilization of Phosphorus from Water and Sediment Using Zirconium-Modified Zeolites. Environmental Science and Pollution Research International, 22, 3606-3619. https://doi.org/10.1007/s11356-014-3604-2

[26] Luo, X., et al. (2016) Adsorption of Phosphate in Water Using One-Step Synthesized Zirconium-Loaded Reduced Graphene Oxide. Scientific Reports, 6, Article No. 39108. https://doi.org/10.1038/srep39108

[27] Gupta, S. and Bhattacharvya, K.G. (2011) Kinetics of Adsorption of Metal Ions on Inorganic Materials: A Review. Advances in Colloid and Interface Science, 162, 39-58. https://doi.org/10.1016/j.cis.2010.12.004

[28] Mao, Y. and Yue, Q. (2016) Kinetic Modelling of Phosphate Adsorption by Preformed in Situ Formed Hydrated Ferric Oxides at Circum-Neutral pH. Scientific Reports, 6, Article No. 35292. https://doi.org/10.1038/srep35292

[29] Foo, K. and Hameed, B. (2010) Insights into the Modeling of Adsorption Isotherm Systems. Chemical Engineering Journal, 156, 2-10.

https://doi.org/10.1016/j.cej.2009.09.013 